\title{
46. COBB MOUNTAIN GEOMAGNETIC POLARITY EVENT AND TRANSITIONS IN THREE DEEP-SEA SEDIMENT CORES FROM THE LAU BASIN ${ }^{1}$
}

\author{
Niels Abrahamsen ${ }^{2}$ and William W. Sager ${ }^{3}$
}

\begin{abstract}
Detailed paleomagnetic investigations are reported for 283 specimens, sampled from three closely spaced Ocean Drilling Program Leg 135 cores from the Lau Basin. These specimens cover three rather similar records of the reversed Cobb Mountain short polarity event, having an age of about 1.12 m.y.

On the basis of a very detailed subsampling every $0.6 \mathrm{~cm}$, we found that the transition times for the Cobb Mountain geomagnetic polarity event, as seen in the three Lau Basin sediment records, appear to have been as short as 0.6-1.0 k.y., although the duration of the normal-polarity event itself lasted only about $17 \pm 4$ k.y. The older $(R$ to $N$ ) transition as well as the younger $\left(\mathrm{N}\right.$ to $\mathrm{R}$ ) transition show virtual geomagnetic paths roughly along the Americas, but shifted some $30^{\circ} \pm 10^{\circ}$ to the east. These paths conflict with Cobb Mountain transition paths recorded in sediments from the Labrador Sea and the North Atlantic, but they are in fair accordance with sediment records from the Celebes and Sulu seas when corrected for differences in site longitude, suggesting that the transitional fields are dominated by nonaxial, high-order spherical harmonics.
\end{abstract}

\section{INTRODUCTION}

Since the documentation in the early 1960 s of the reality of geomagnetic polarity reversals (Cox et al., 1963), details in records of the transitional behavior of the magnetic field between two polarities have been interesting subjects for research, as such records offer the experimental background for a possible understanding of the geomagnetic core dynamo processes during reversals.

Because of the discrete nature of volcanic eruptions and the relatively short duration of the polarity transition time of only a few thousand years, few volcanic records investigated (Mankinen et al., 1985; Prevot et al., 1985) have had sufficient numbers of eruptive flow units during the transition to yield a high-resolution record of transitional field behavior.

Owing to the more continuous nature of deep-sea sedimentation, numerous transition records have been examined in sediment cores. Because the process by which sediments acquire remanent magnetization is poorly understood, some question exists as to the fidelity of such records. However, detailed comparisons of reversals suggest that sediments can be accurate recorders of transition directions (e.g., Verosub, 1982; Tric et al., 1991; Clement, 1992; Clement and Martinson, 1992). Perhaps the two most important factors affecting the quality of transition records in sediments are (1) sedimentation rate and (2) homogeneity and suitability of the magnetic grains as magnetic field recorders.

In recent years, several studies have been published that focus on the details of reversals as recorded at different sites on the globe in the search for systematic patterns of either dipolar or nondipolar behavior of the transitional field (e.g., Hoffman, 1991, 1992; Clement, 1992). One important question has been the symmetry of the transition field: is it dipolar or nondipolar? Another has been whether or not preferred paths are present for the virtual geomagnetic poles (VGPs) at different sites and during different transitions (Laj et al., 1991; Tric et al., 1991; Valet et al., 1992). Because of the scarcity of detailed transition records, noise in the geological records, and statis-

\footnotetext{
${ }^{1}$ Hawkins, J., Parson, L., Allan, J., et al., 1994. Proc. ODP, Sci. Results, 135: College Station, TX (Ocean Drilling Program).

${ }^{2}$ Department of Earth Sciences, Aarhus University, Finlandsgade 8, DK-8200 Arhus N, Denmark.

${ }^{3}$ Departments of Oceanography and Geophysics, Texas A\&M University, College Station, TX 77843 , U.S.A.
}

tical problems, much work still has to be done in this field before reliable conclusions may be drawn.

The purpose of this paper is to present and discuss detailed data from the Cobb Mountain normal geomagnetic event as it has been recorded in three deep-sea sediment cores from the Lau Basin. This reversal is notable because it appears to be a short event, not generally recognized in the otherwise well-documented Pliocene-Pleistocene polarity reversal time scale. Moreover, detailed records of this event have now been published from deep-sea sediments from the North Atlantic nearly antipodal to the sites in the Lau Basin (Clement and Kent, 1987; Clement and Martinson, 1992), from the Celebes and Sulu seas (Hsu et al., 1990) some $60^{\circ} \mathrm{W}$ of the Lau Basin, as well as from volcanics from Tahiti (Chauvin et al., 1990) about $30^{\circ} \mathrm{E}$ of the Lau Basin.

The geographical position of Sites 837,838 , and 839 is shown in Figure 1. The Lau Basin is a young (< ca. $5 \mathrm{Ma}$ ) backarc basin (Leg 135 Shipboard Scientific Party, 1991; Parson, Hawkins, Allan, et al., 1992) situated in the western south central Pacific, between the Lau Ridge and the Tonga Arc between $15^{\circ}$ to $24^{\circ} \mathrm{S}$ and $175^{\circ}$ to $178^{\circ} \mathrm{W}$.

\section{THE COBB MOUNTAIN EVENT}

The Cobb Mountain (CM) event is a short normal-polarity event within the reversed Matuyama Chron, which was noted as a shortwavelength seafloor anomaly by Rea and Blakely (1975). Based on a study of volcanics in northern California, the event was later named the Cobb Mountain Event by Mankinen et al. (1978), who also dated the event by $\mathrm{K}-\mathrm{Ar}$ to $1.12 \pm 0.02$ m.y., differentiating it from the slightly younger Jaramillo Event from 0.98 to $0.91 \mathrm{Ma}$ (Harland et al., 1989).

Two detailed studies of the Cobb Mountain Event, from the North Atlantic at Deep Sea Drilling Project (DSDP) Site 609 (Clement and Kent, 1987) and from the southern Labrador Sea at Ocean Drilling Program (ODP) Site 647 (Clement and Martinson, 1992), separated by $12^{\circ}$, showed very similar dipolar transitional field behavior of the Cobb Mountain Event at the two sites. Clement and Martinson (1992) used a quantitative correlation technique to establish statistically the degree of similarity between the two records and found that the records showed large-scale changes in the field that could not be distinguished from dipolar changes, given the proximity of the two sites. Their results also showed that deep-sea sediments are capable of providing high-resolution records of the geomagnetic field behavior. Reexamining the record from the North Atlantic (Clement and Kent, 1987), Clement and Martinson (1992) further suggested the 


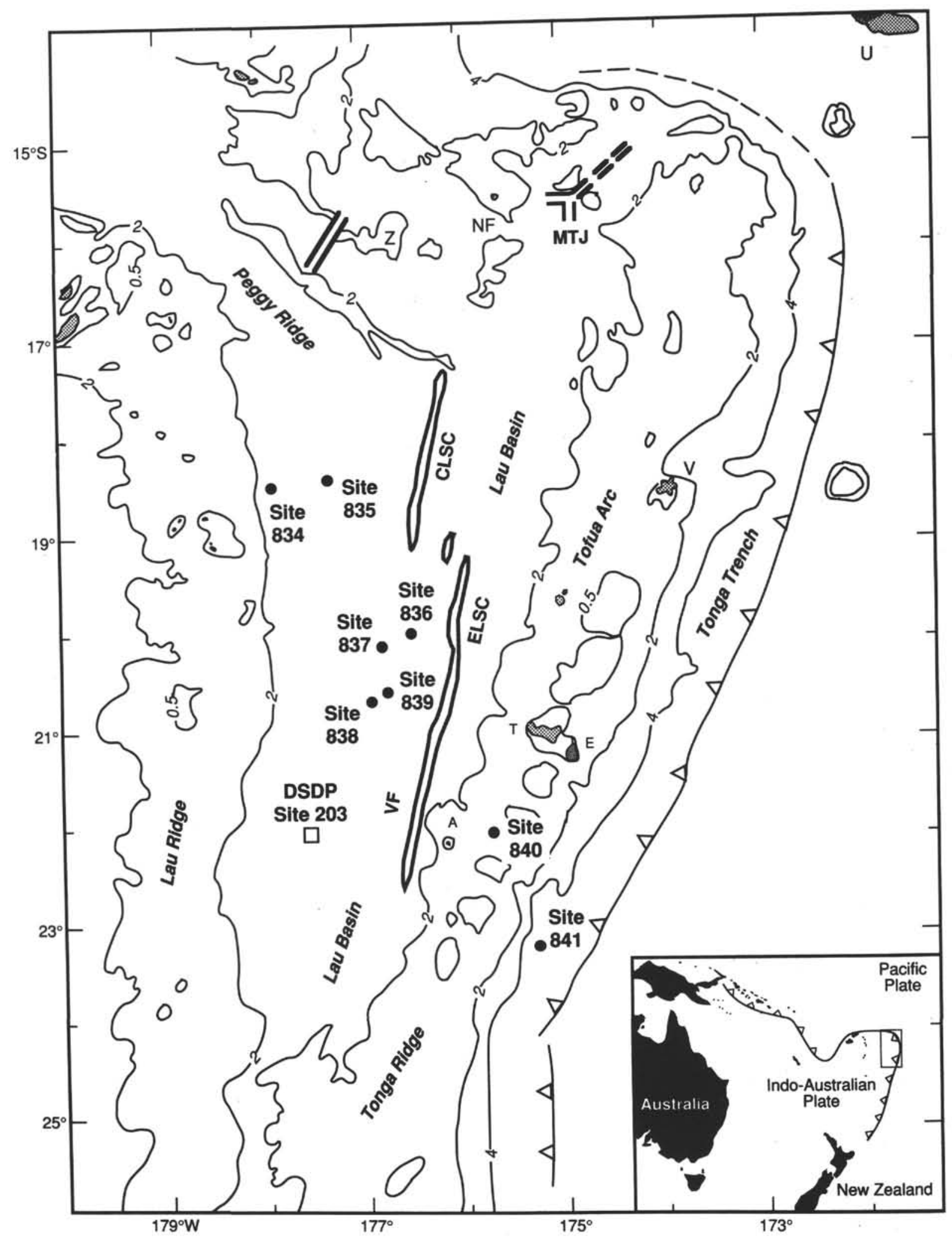

Figure 1. Index map of the Lau Ridge Basin region, indicating the Leg 135 drill sites (834 through 841 ). The Central Lau and Eastern Lau spreading centers (CLSC and ELSC), Valu Fa Ridge (VF), Zephyr Shoal (Z), and Mangatolu Triple Junction (MTJ) are also shown. Islands include Niuafo' ou (NF), Vava'u (V), Tongatapu (T), 'Eua (E), 'Ata (A), and Upolu (U), Western Samoa. Water depth contours in kilometers. From Parson, Hawkins, Allan, et al. (1992). 
presence of two preferred transitional field configurations, as the field appears to change from one configuration to the other for several reversals and then back to the original configuration.

Hsu et al. (1990) have reported detailed transition studies of the Cobb Mountain Event as recorded in two ODP cores from the Celebes and Sulu seas. Although the two sites in their study are situated fairly close to each other (only $3.9^{\circ}$ apart), these records of the transitional fields were found to be quite different, and their VGPs were also different from that of the North Atlantic. Hsu et al. (1990) also found a brief rebound after the onset reversal at the Celebes Sea site, and they concluded that the transitional fields for the Cobb Mountain Event were nonaxisymmetrical. In contrast, comparing the results from the North Atlantic, the Celebes and Sulu seas, and Tahiti, Clement (1992) concluded that sequences of VGP positions from the North Atlantic sediments and volcanics from Tahiti (Chauvin et al., 1990) are very similar and provide evidence of dipolar transitional fields during the Cobb Mountain reversals.

\section{SAMPLING AND MAGNETIC TECHNIQUES}

Based on shipboard pass-through cryogenic magnetic measurements on archive halves of the sediment cores (for more details, see Parson, Hawkins, Allan, et al., 1992), which were measured and stepwise partially demagnetized in alternating magnetic fields up to $15 \mathrm{mT}$ (Fig. 2), three sections were selected for further, onshore studies of the Cobb Mountain magnetic event. The criteria for selecting the chosen sections for transitional magnetic studies were (1) that the section had to be characterized by relatively high rates of sedimentation, (2) it had to be stratigraphically undisturbed, and (3) it had to have a normal ("well-behaved") pass-through cryogenic magnetic record. The pass-through measurements clearly showed the presence of the Cobb Mountain Event in all studied sections, but the 15-mT limit on alternating field (AF) demagnetization allowed by ODP was not always sufficient to remove overprints completely.

Detailed sampling of the three Cobb Mountain sections was made at the ODP repository at College Station. Cube holders of polystyrene with a $1-\mathrm{cm}^{3}$ volume and $1.2-\mathrm{cm}$ external width were used for sampling. Lining up the holders side by side in two rows, cubes of the sediment were carefully cut with a spatula and then encapsulated in the holder. Most of the samples were juxtaposed in two parallel rows, the stratigraphic steps between neighboring samples thus typically being $0.6 \mathrm{~cm}$. The open end of the cube was sealed by stretching a thin piece of laboratory parafilm across it, which adhered well enough to the sides of the cube to allow general laboratory treatment of the samples.

After measuring the magnetic susceptibility in a Bartington MS2 magnetic susceptibility meter, the natural remanent magnetization (NRM) was measured in a three-axis cryogenic magnetometer (CTF Model DRM-453). Subsequently, the samples were stepwise partially AF-demagnetized by a Schonstedt Model GSD-1 demagnetizer, and the remaining remanent magnetization (RM) was remeasured; this procedure was repeated in steps of $10 \mathrm{mT}$ up to AF values of between 60 and $100 \mathrm{mT}$. After this, the saturated induced remanent magnetization (SIRM) was produced in a peak field of $1.2 \mathrm{~T}$ by an impulse magnetizer (ASC Scientific Model IM-10); the sample was again measured on the cryogenic magnetometer to give the SIRM, and from this state it was finally again partially AF-demagnetized in $10 \mathrm{mT}$ and remeasured. The more high-coercive part of the SIRM (SIRM-10) was thus obtained. A few representative samples from each transition were also subjected to stepwise increasing DC magnetic fields up to $1 \mathrm{~T}$ in order to obtain SIRM acquisition curves.

\section{LITHOSTRATIGRAPHY OF SECTIONS $\mathrm{C} 1, \mathrm{C} 2$, AND C3}

The three selected sections we studied all display clear Cobb Mountain Events in the pass-through data. They are (1) Cobb Mountain
Section C1, Section 135-837A-3H-5; (2) Cobb Mountain Section C2, Section 135-836A-3H-6; and (3) Cobb Mountain Section C3, Section 135-839A-5H-6. The three sites are situated within $60 \mathrm{~km}$ of one another (Fig. 1).

The sedimentary sequence cored at Site 837 consists of $82 \mathrm{~m}$ of clayey nannofossil ooze and vitric volcaniclastics ranging in age from the Holocene to the latest Pliocene (Parson, Hawkins, Allan, et al., 1992). Turbidites, up to $17 \mathrm{~m}$ in thickness, make up about $60 \%$ of the sedimentary sequence. The sedimentary sequence at Site 837 was divided into two lithologic units, based mainly on differences in the abundance of volcaniclastic deposits. Unit I ( $0-13.5 \mathrm{mbsf})$ is dominated by clayey nannofossil oozes, whereas Unit II (13.5-82.0 mbsf) consists of nannofossil ooze punctuated by thick, graded, volcaniclastic sands and silts interpreted as turbidites. Unit II is divided into five subunits, each of which defines upward-fining depositional cycles. The Cobb Mountain Section C1 (24.3-24.7 mbsf) is found in Subunit IIB (21.0-35.2 mbsf), which consists of $5.9 \mathrm{~m}$ of dark brown clayey nannofossil ooze, overlying $8.3 \mathrm{~m}$ of pale brown to gray vitric silt.

The dark brown clayey nannofossil oozes consist of about $30 \%$ clay and up to $60 \%$ calcareous nannofossils. Foraminifers (about 8 vol\%) and volcanic glass (up to $2 \mathrm{vol} \%$ ) occur in much smaller quantities. Trace amounts of accessory minerals such as opaques and mafics are also generally present. The clayey nannofossil ooze is stained dark brown by iron and manganese oxyhydroxides, which occur as small aggregates or grain coatings within the sediments. The sediment, which is firm and slightly mottled throughout, contains rare weathered pumice lapilli and mud clasts up to $1 \mathrm{~cm}$ in diameter. Mud clasts are particularly common in the upper part of the unit between 21 and $22 \mathrm{mbsf}$, but they are rare in the Cobb Mountain part of the unit.

The sedimentary sequence cored at Site 838 (Parson, Hawkins, Allan, et al., 1992) consists of $103 \mathrm{~m}$ of vitric volcaniclastic sediments and clayey nannofossil oozes ranging in age from the middle Pleistocene to the upper Pliocene. The sedimentary sequence was divided into lithologic units based on differences in texture, structure, and composition and on the varying abundance of volcaniclastic deposits. The Cobb Mountain Event is within the uppermost unit (21.7-22.0 mbsf), which is dominated by clayey nannofossil ooze with occasional interbeds of vitric sand and vitric fine ash with foraminifers. The clayey nannofossil ooze is composed mainly of calcareous nannofossils (47$52 \mathrm{vol} \%$ ), clay ( $40-45 \mathrm{vol} \%$ ), and planktonic foraminifer tests and test debris (up to $8 \mathrm{vol} \%$ ). The ooze is generally homogeneous, although clasts of altered pumice (up to $2 \mathrm{~cm}$ across) are present and bioturbation mottling occurs. The ooze contains an average of $55 \%-60 \% \mathrm{CaCO}_{3}$. The clayey nannofossil ooze is stained dark brown to very dark grayish brown because of the presence of iron oxyhydroxides.

The sedimentary sequence recovered at Site 839 (Parson, Hawkins, Allan, et al., 1992) consists of $215 \mathrm{~m}$ of clayey nannofossil ooze, turbiditic vitric sands and silts, volcanic gravels, and rare pyroclastic fallout ashes. The age of the sedimentary sequence ranges from the middle Pleistocene to the upper Pliocene. Once again, the sedimentary sequence was divided into lithologic units based primarily on the presence or absence of volcaniclastic sands and silts.

The Cobb Mountain Event is within lithologic Unit II (41.0-41.3 mbsf), which is distinguished from Unit I by its very high content of volcaniclastic material. The unit comprises a sequence of generally thick vitric sand and silts, with some clayey nannofossil ooze interbeds. Clayey nannofossil ooze constitutes about $25 \%-30 \%$ of the sequence.

The clayey nannofossil ooze is dark brown and appears to be homogeneous over long intervals, although a few short intervals show faint mottling, one of which includes the Cobb Mountain Event of Section C3. The ooze also contains a few isolated commonly altered pumice clasts. The clayey nannofossil ooze contains $50 \%$ calcareous nannofossils, and up to $10 \%$ planktonic foraminifers and test debris. In total, this makes up the $55 \%-60 \% \mathrm{CaCO}_{3}$ of the sediment. The noncarbonate fraction consists of clay (35-40 vol\%) and accessory minerals, mainly pyroxenes (up to $5 \mathrm{vol} \%$ ). 


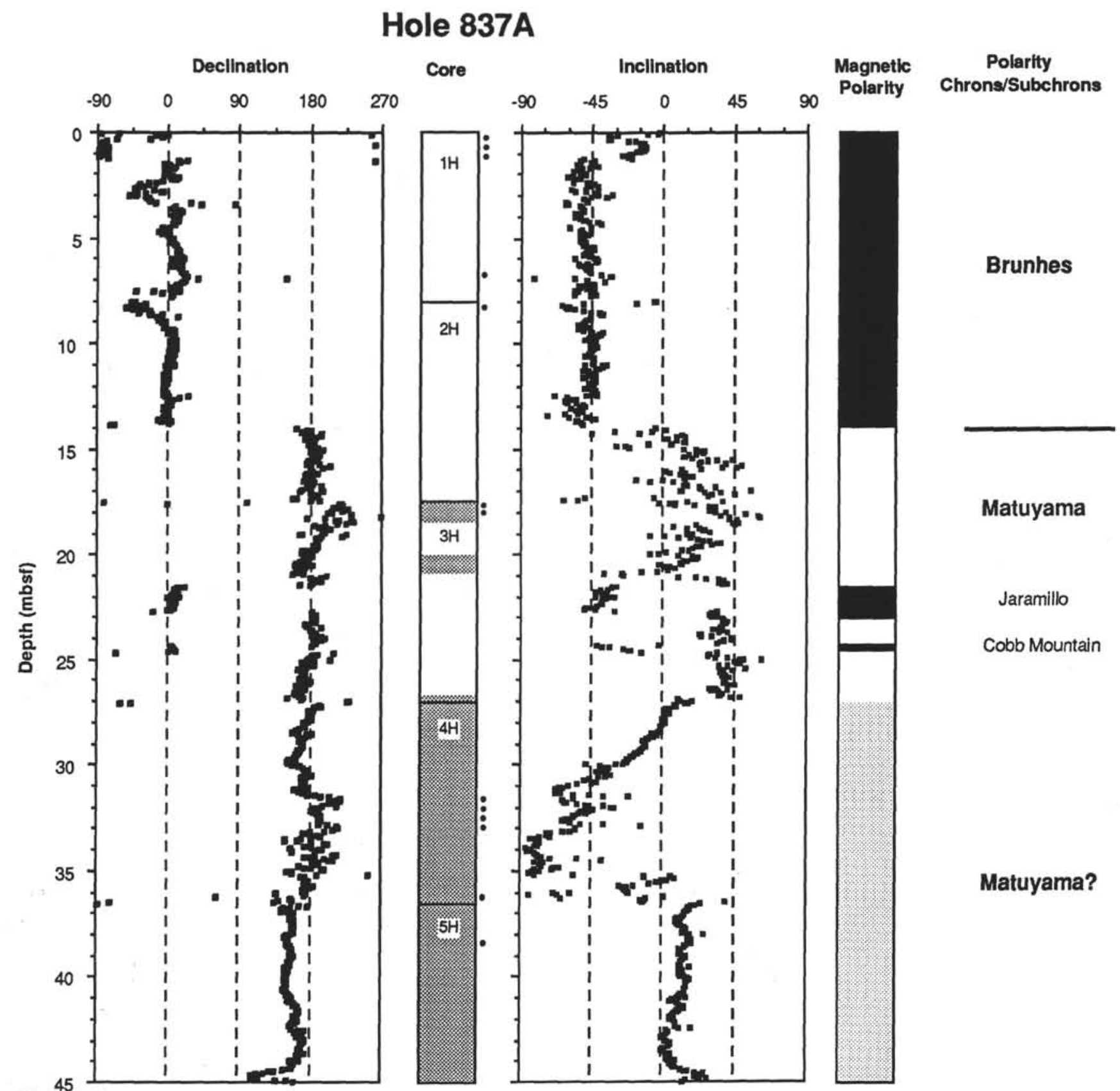

Figure 2. Magnetostratigraphic plots of sediments from Holes 837A, 838A, and 839A. Magnetic declination and inclination are plotted vs. depth in the wide columns on left and right, respectively. These measurements were made with a $2 \mathrm{G}$ pass-through cryogenic magnetometer with a 5 - $\mathrm{cm}$ spacing after AF demagnetization at $15 \mathrm{mT}$. Column in middle shows core boundaries; fine stipple denotes ash turbidites and coarse stipple represents pumiceous ash turbidites. Declination values for Cores $1 \mathrm{H}$ through $3 \mathrm{H}$ in each hole are arbitrary and have been reoriented to place normal-polarity declinations at zero. Cores deeper than $3 \mathrm{H}$ have been azimuthally oriented with a magnetic compass tool (see Parson, Hawkins, Allan, et al., 1992). Dots to the right of center column show where drilling disturbance of the cores is severe. Column at right shows interpreted magnetic polarity, white is reversed polarity, light stipple shows core of probably reversed polarity, and hachures denote indeterminate polarity. (Figures modified from Parson, Hawkins, Allan, et al., 1992).

\section{MAGNETIC RESULTS}

The magnetic properties of the Lau Basin sediments, as investigated in the Leg 135 holes in general, is described in detail elsewhere (Abrahamsen and Sager, this volume; Sager and Abrahamsen, this volume; Parson, Hawkins, Allan, et al., 1992). The description below relates to the clayey nannofossil ooze only, in which the Cobb Mountain Event was investigated in more detail by the subsampling.

\section{Duration of the Cobb Mountain Event}

The apparent average deep-sea sedimentation rates fluctuate drastically in the area owing to short-time irregular contributions of volcaniclastics. In addition, cycles in magnetic susceptibility (Parson, Hawkins, Allan, et al., 1992) suggest that longer term, climatically driven depositional variations may be present. To obtain an average deposition rate, age vs. depth curves were constructed using reversals 
Hole 838A

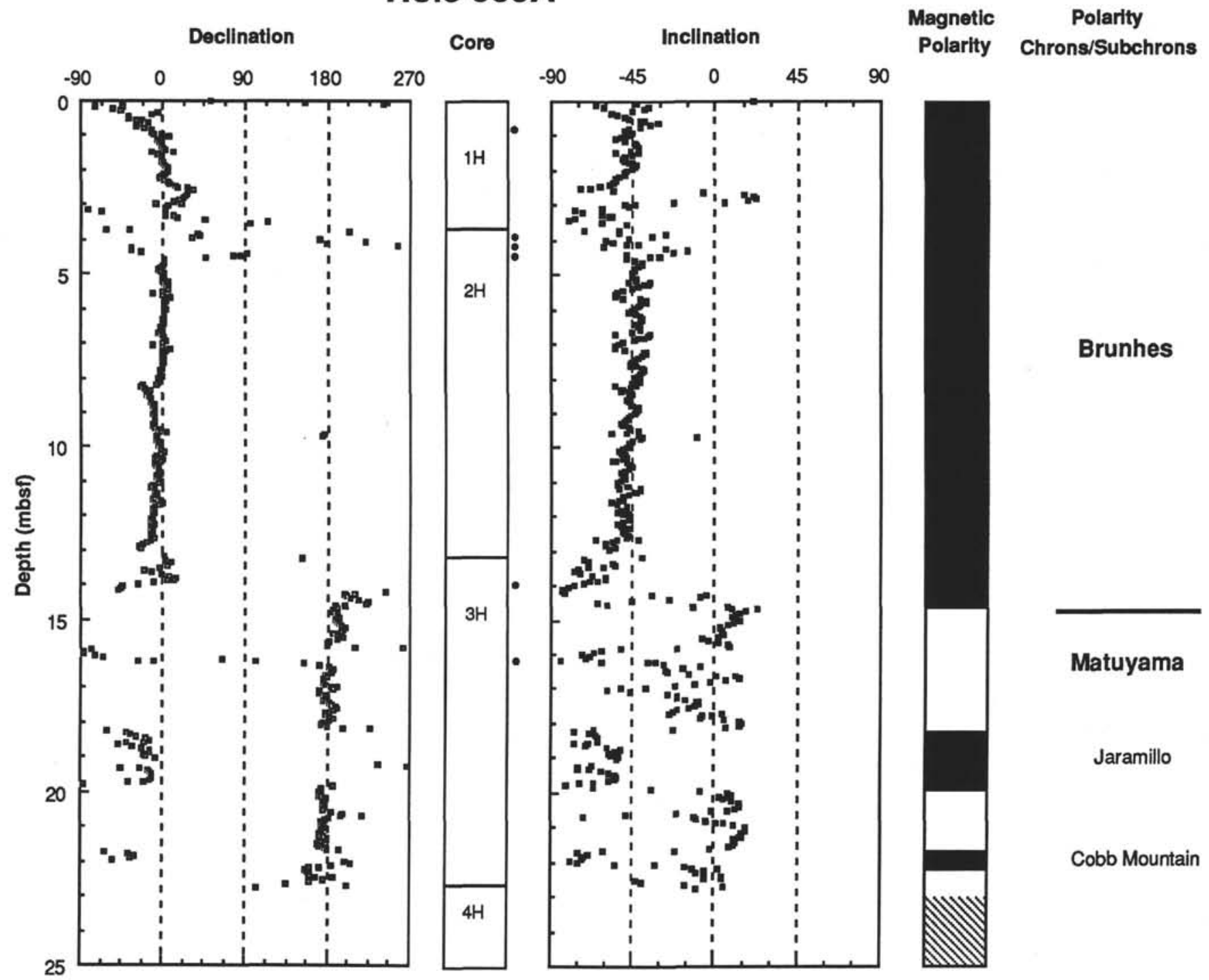

Figure 2 (continued).

recorded by the pass-through cryogenic magnetometer (Fig. 2; see also the paleomagnetic chapters in Parson, Hawkins, Allan, et al., 1992).

In Table 1, values and details of local depths for the Cobb Mountain Event in the three records (based on the well-defined change in declination, see below) are summarized, as well as estimates of uncertainties based on assumed accuracies in the age $( \pm 0.01 \mathrm{Ma})$ and depth determinations from the pass-through magnetometer $( \pm 0.05 \mathrm{~m})$.

Applying the Cobb Mountain Event age of $1.12 \mathrm{Ma}$, and the termination of the Jaramillo Chron (CR1R-1[y]) of $0.91 \mathrm{Ma}$, three estimates are found for the duration of the Cobb Mountain Event between 12.9 and $21.3 \mathrm{k} . \mathrm{y}$., the average being $17 \pm 4$ k.y.

Thus, the Cobb Mountain Event is one of the shortest events recorded. Many short polarity events have proven difficult to document over large areas (Champion et al., 1988; Harland et al., 1989; Thouveny and Creer, 1992). However, the Cobb Mountain Event has now been found in the Atlantic, as well as in the North and South Pacific, so its global nature cannot be in doubt.

\section{Magnetic Results from Section C1}

Rock magnetic results from Cobb Mountain Section $\mathrm{C} 1$ are plotted vs. depth in Figure 3. The modified $Q$-ratio is the ratio between the
NRM intensity and the magnetic susceptibility, $Q=\mathrm{J} / \mathrm{susceptibility;}$ the ratio $Q_{10}=J_{10} /$ susceptibility gives the corresponding ratio after AF demagnetization at $10 \mathrm{mT}$.

The susceptibility, $Q$-ratio, and $J /$ SIRM ratio do not show strong systematic variations with depth, the scatter probably being caused by small fluctuations in magnetic properties such as magnetic miner-

Table 1. Estimates of the duration of the Cobb Mountain Event, determined from deposition rates for Sections C1, C2, and C3.

\begin{tabular}{|c|c|c|c|c|}
\hline & $\begin{array}{l}\text { Hole, core, } \\
\text { section }\end{array}$ & $\begin{array}{l}\text { Depth of CM } \\
\text { Event in } \\
\text { section }(\mathrm{cm})\end{array}$ & $\begin{array}{c}\text { Deposition rate } \\
(\mathrm{mm} / \mathrm{k} . \mathrm{y} .) \text { between } \\
\mathrm{Jy}=0.91 \mathrm{Ma} \text { and } \\
\mathrm{CM}_{0}=1.12 \mathrm{Ma}\end{array}$ & $\begin{array}{c}\text { Duration of } \\
\text { CM Event } \\
\text { (k.y.) }\end{array}$ \\
\hline $\mathrm{Cl}$ & $135-837 \mathrm{~A}-3 \mathrm{H}-5$ & $84-117$ & $15.5 \pm 0.5$ & 21.3 \\
\hline $\mathrm{C} 2$ & $135-838 \mathrm{~A}-3 \mathrm{H}-6$ & 99-130 & $18.5 \pm 0.5$ & 16.8 \\
\hline \multirow[t]{2}{*}{$\mathrm{C} 3$} & $135-839 \mathrm{~A}-5 \mathrm{H}-6$ & $51-79$ & $25 \pm 2$ & 12.9 \\
\hline & & & Mear & $17.0 \pm 4.2$ \\
\hline
\end{tabular}

Notes: Data are based upon the reversal stratigraphy between Jaramillo (young) and Cobb Mountain. For Section C3 the deposition rate is corrected for the presence of ca. $1 \mathrm{~m}$ of volcaniclastic sediments between 39 and $40 \mathrm{mbsf}$. CM $=$ Cobb Mountain, Jy = end of Jaramillo Subchron $(0.91 \mathrm{Ma}) . \mathrm{CM}_{0}=$ age of $\mathrm{CM}$ (1.12 Ma). 


\section{Hole 839A}

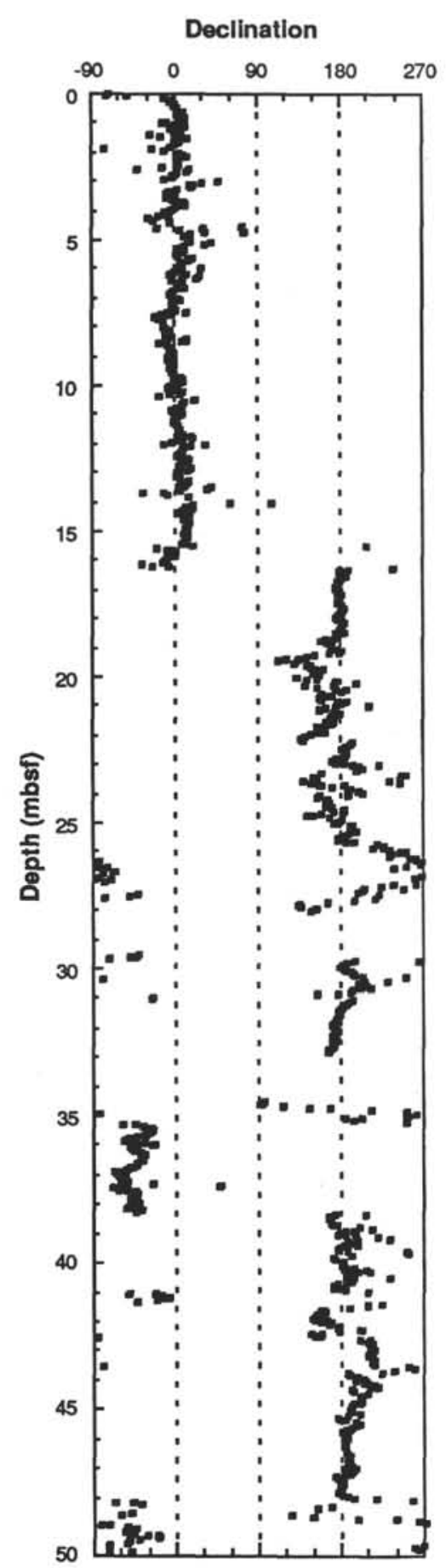

\section{Core} $-90$

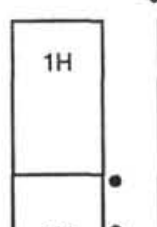

\begin{tabular}{rrrrr}
90 & -45 & 0 & $45 \quad 90$ \\
\hline & 4 & 9
\end{tabular}

Magnetic Polarity

\section{(1)}

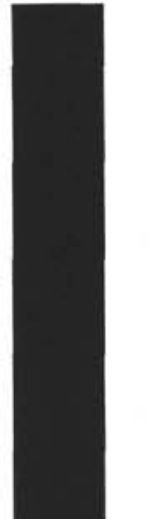

Brunhes
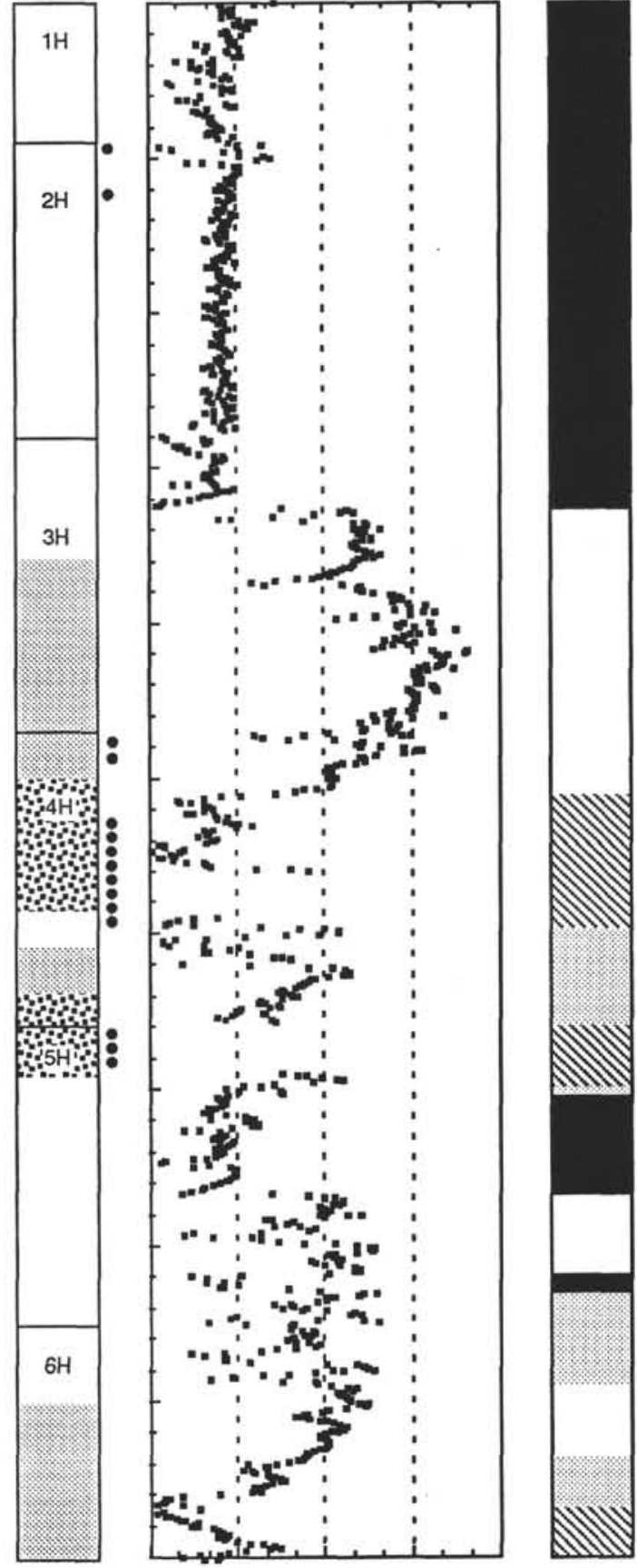

Polarity

Matuyama

Jaramillo

Cobb Mountain

Chrons/Subchrons

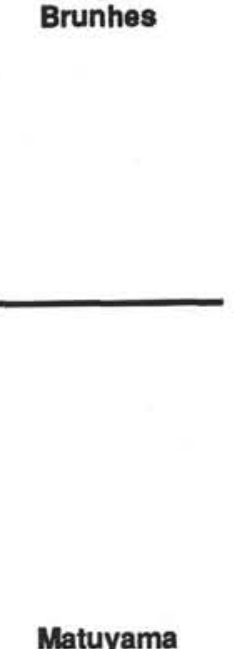

Figure 2 (continued).

alogy, concentration, and grain size as well as experimental noise; hence, we see only minor systematic magneto-mineralogical variations with depth. In contrast, the normalized ratio after AF demagnetization at $10 \mathrm{mT}, J_{10} / \mathrm{SIRM}$ (and also the ratio $Q_{10}$ ), shows lower values at $117-107$ and $84-79 \mathrm{~cm}$, which correlates very well with the two polarity transitions (see below).

The ratio $J_{10} /$ SIRM (heavy line, Fig. 3 ) is likely to reduce possible influence from such variations as mineralogy, concentration, and grain size in the sediment, leaving the influence of fluctuations in the ambient field only (cf. Tric et al. [1992], who showed $J_{20} /$ SIRM to be a useful indicator of paleointensity in deep-sea sediments). Hence, the normalized ratio $J_{10} /$ SIRM may be taken as an estimate of the relative paleointensity of the geomagnetic field. The very close correspondence between the $J_{10} / \mathrm{SIRM}$ and $Q_{10}$ ratios further suggests that the latter ratio also may be a useful (and easily obtained) indicator of paleointensity variations of the geomagnetic field. At the levels mentioned, 
Cobb Mountain (Section C1)

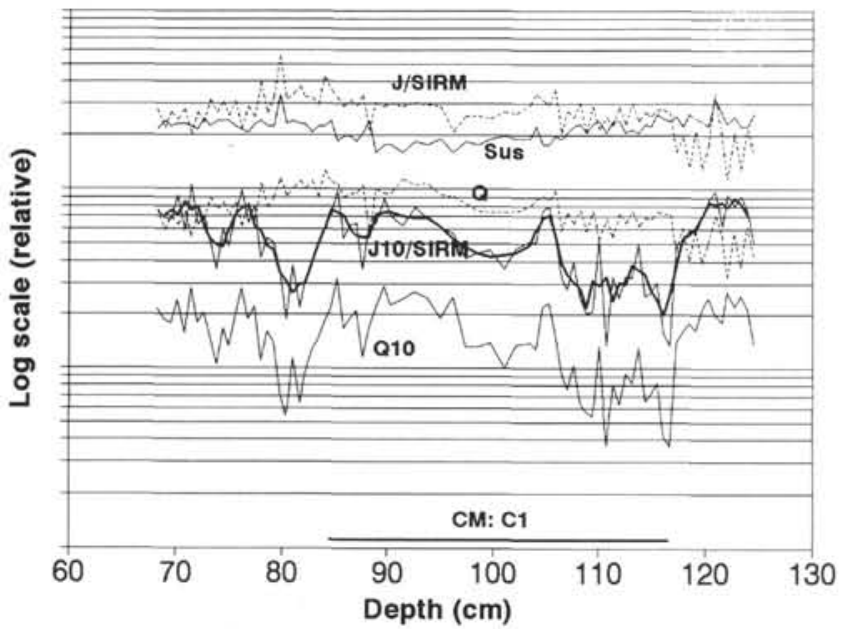

Figure 3. Rock-magnetic properties vs. depth of samples from Section $\mathrm{Cl}(\mathrm{CM}$ Event at $84-117 \mathrm{~cm}$; cf. Table 1). $Q=J(\mathrm{NRM}) /$ susceptibility; $Q_{10}=J_{10} /$ susceptibility; $J_{10}$ is the remanent magnetization intensity after AF demagnetization at $10 \mathrm{mT}$; the normalized $J_{10} / \mathrm{SIRM}$ ratio is taken as a measure of the relative paleointensity of the geomagnetic field (heavy line is a 3-point moving average). Units are given in Table 2.

Table 2. Detailed magnetic information for each specimen in Section C1.

\begin{tabular}{|c|c|c|c|c|c|c|c|}
\hline $\begin{array}{l}\text { Sample } \\
\text { no. }\end{array}$ & $\begin{array}{c}\text { Depth } \\
+23.5 \mathrm{~m}(\mathrm{~cm})\end{array}$ & $\begin{array}{c}\mathrm{J}_{0} \\
(\mathrm{~mA} / \mathrm{m})\end{array}$ & $\begin{array}{c}\mathrm{J}_{10} \\
(\mathrm{~mA} / \mathrm{m})\end{array}$ & $\begin{array}{l}\text { Susceptibility } \\
(\text { cgs }) \times 10^{-5}\end{array}$ & $\begin{array}{l}\text { SIRM } \\
(\mathrm{A} / \mathrm{m})\end{array}$ & $\begin{array}{l}\text { D1234 } \\
\left(-160^{\circ}\right)\end{array}$ & I1 234 \\
\hline 1 & 68.3 & 16.64 & 4.59 & 2.7 & 5.96 & 175 & 34 \\
\hline 2 & 69.0 & 14.00 & 4.43 & 3.0 & 6.45 & 161 & 35 \\
\hline 3 & 69.6 & 15.75 & 3.95 & 2.8 & 5.82 & 183 & 32 \\
\hline 4 & 70.2 & 14.63 & 5.54 & 2.9 & 6.03 & 188 & 35 \\
\hline 5 & 70.8 & 17.41 & 3.61 & 2.9 & 6.20 & 180 & 38 \\
\hline 6 & 71.4 & 12.12 & 6.35 & 2.8 & 6.04 & 162 & 42 \\
\hline 7 & 72.0 & 16.32 & 3.84 & 2.7 & 6.03 & 194 & 42 \\
\hline 8 & 72.6 & 16.69 & 5.05 & 3.1 & 7.14 & 186 & 26 \\
\hline 9 & 73.2 & 19.95 & 3.28 & 2.8 & 6.33 & 146 & 30 \\
\hline 10 & 73.8 & 18.44 & 2.50 & 3.0 & 6.96 & 164 & 49 \\
\hline 11 & 74.4 & 20.11 & 3.94 & 3.0 & 6.56 & 174 & 49 \\
\hline 12 & 75.0 & 16.91 & 3.14 & 3.0 & 6.61 & 157 & 54 \\
\hline 13 & 75.6 & 18.78 & 4.34 & 2.8 & 6.03 & 200 & 35 \\
\hline 14 & 76.2 & 13.28 & 6.03 & 2.7 & 6.13 & 180 & 34 \\
\hline 15 & 76.8 & 17.19 & 3.84 & 2.6 & 6.01 & 165 & 31 \\
\hline 16 & 77.4 & 15.90 & 5.16 & 2.9 & 6.38 & 173 & 24 \\
\hline 17 & 78.0 & 25.30 & 2.62 & 3.0 & 6.35 & 218 & 30 \\
\hline 18 & 78.6 & 17.47 & 3.57 & 2.8 & 6.64 & 214 & 26 \\
\hline 19 & 79.2 & 20.13 & 3.10 & 2.8 & 6.19 & 172 & 34 \\
\hline 20 & 79.8 & 38.51 & 2.38 & 4.2 & 6.82 & 237 & -36 \\
\hline 21 & 80.4 & 20.93 & 1.25 & 2.9 & 6.68 & 205 & 21 \\
\hline 22 & 81.0 & 23.92 & 2.71 & 3.0 & 7.08 & 303 & -33 \\
\hline 23 & 81.6 & 25.58 & 1.47 & 2.9 & 6.79 & 179 & -49 \\
\hline 24 & 82.2 & 23.13 & 2.15 & 2.9 & 7.07 & 128 & -60 \\
\hline 25 & 82.8 & 22.76 & 2.63 & 2.6 & 6.92 & 186 & -25 \\
\hline 26 & 83.4 & 20.12 & 3.22 & 2.8 & 6.77 & 233 & -6 \\
\hline 27 & 84.0 & 28.30 & 4.06 & 2.8 & 6.65 & 120 & -59 \\
\hline 28 & 84.6 & 26.12 & 5.20 & 3.0 & 7.17 & -17 & -43 \\
\hline 29 & 85.2 & 19.62 & 5.85 & 2.3 & 5.96 & -23 & -47 \\
\hline 30 & 85.8 & 17.85 & 3.29 & 2.5 & 6.19 & -2 & -36 \\
\hline 31 & 86.4 & 18.75 & 3.80 & 2.5 & 5.94 & -24 & -48 \\
\hline 32 & 87.0 & 17.39 & 3.89 & 2.3 & 6.03 & -24 & -32 \\
\hline 33 & 87.6 & 21.86 & 2.35 & 2.6 & 6.51 & -42 & -33 \\
\hline 34. & 88.2 & 13.49 & 4.01 & 3.0 & 6.41 & -5 & -48 \\
\hline 35 & 88.8 & 15.98 & 3.40 & 2.0 & 5.26 & -11 & -32 \\
\hline 36 & 89.6 & 16.50 & 5.05 & 2.2 & 5.71 & -35 & -50 \\
\hline 37 & 90.2 & 16.69 & 3.95 & 2.2 & 5.61 & -19 & -33 \\
\hline 38 & 91.4 & 18.09 & 3.91 & 2.0 & 6.26 & 11 & -62 \\
\hline 39 & 92.6 & 19.12 & 4.95 & 2.3 & 6.29 & -16 & -30 \\
\hline 40 & 93.8 & 18.65 & 4.32 & 2.2 & 6.35 & -9 & -25 \\
\hline 41 & 95.0 & 17.59 & 3.67 & 2.4 & 6.00 & 25 & -42 \\
\hline 42 & 96.2 & 14.52 & 3.98 & 2.0 & 6.95 & -19 & -9 \\
\hline 43 & 97.4 & 15.00 & 2.42 & 2.3 & 5.82 & 17 & -1 \\
\hline 44 & 98.6 & 13.22 & 2.31 & 2.2 & 5.16 & -18 & 21 \\
\hline 45 & 99.8 & 14.19 & 2.66 & 2.4 & 5.76 & 3 & 7 \\
\hline
\end{tabular}

therefore, the geomagnetic field appears to have been reduced to about $20 \%$ (at $116 \mathrm{~cm}$ ) and $30 \%$ (at $81 \mathrm{~cm}$ ), respectively, of the normal geomagnetic field intensity.

Figure 4 illustrates characteristic examples of individual sample behavior during AF demagnetization. Typically, after $10 \mathrm{mT}$, the direction of the remanence remains fairly stable and the polarity is well defined; during further demagnetization, a unidirectional reduction toward the origin is generally observed. The rapid decay of intensity during AF demagnetization with median destructive fields (MDF) of typically 6-7 mT, together with the SIRM acquisition curves in Figure 5, shows that saturation occurs between 0.2 and $0.3 \mathrm{~T}$, and that the dominant carrier of the remanence is fine-grained magnetite.

The directional results after AF demagnetization at $10,20,30$, and $40 \mathrm{mT}$ are shown in Figure 6 for all specimens from Section C1. To average out errors originating from experimental noise caused by the small sample volume, the low intensity after AF demagnetization (the average of $J_{10}$ being $4 \mathrm{~mA} / \mathrm{m}$ ), and statistical errors, the mean of the four demagnetization levels mentioned is adopted as the best estimate of the primary magnetization; this mean for each specimen is shown by the full heavy line. As the true azimuthal orientation of the core is not known, the declination has been rotated by $-160^{\circ}$ to match the mean of the nontransitional (dipolar) parts of the record to $0^{\circ}$ and $180^{\circ}$, respectively. Details for all samples are listed in Table 2.

The declination shows a rather clearcut polarity behavior with the older R-N polarity transition (as the site is situated on the Southern Hemisphere) at $116 \mathrm{~cm}$, and the younger N-R polarity transition at 84

\begin{tabular}{|c|c|c|c|c|c|c|c|}
\hline $\begin{array}{c}\text { Sample } \\
\text { no. }\end{array}$ & $\begin{array}{c}\text { Depth } \\
+23.5 \mathrm{~m}(\mathrm{~cm})\end{array}$ & $\begin{array}{c}\mathrm{J}_{0} \\
(\mathrm{~mA} / \mathrm{m})\end{array}$ & $\begin{array}{c}\mathrm{J}_{10} \\
(\mathrm{~mA} / \mathrm{m})\end{array}$ & $\begin{array}{l}\text { Susceptibility } \\
(\mathrm{cgs}) \times 10^{-5}\end{array}$ & $\begin{array}{l}\text { SIRM } \\
(\mathrm{A} / \mathrm{m})\end{array}$ & $\begin{array}{l}\text { D1234 } \\
\left(-160^{\circ}\right)\end{array}$ & I1 234 \\
\hline 46 & 101.1 & 14.81 & 2.00 & 2.5 & 5.53 & -24 & 12 \\
\hline 47 & 102.2 & 14.35 & 2.57 & 2.4 & 5.47 & 16 & 24 \\
\hline 48 & 103.5 & 15.21 & 2.63 & 2.4 & 5.16 & -18 & -6 \\
\hline 49 & 104.1 & 19.21 & 2.85 & 2.8 & 5.67 & 9 & 2 \\
\hline 50 & 104.7 & 15.86 & 3.85 & 2.2 & 5.03 & 3 & -31 \\
\hline 51 & 105.3 & 15.21 & 4.10 & 2.2 & 5.12 & -7 & -35 \\
\hline 52 & 105.9 & 19.58 & 3.07 & 2.5 & 5.41 & -40 & -33 \\
\hline 53 & 106.5 & 11.16 & 1.77 & 2.4 & 5.40 & 37 & 22 \\
\hline 54 & 107.1 & 15.39 & 1.57 & 2.6 & 5.65 & 13 & 17 \\
\hline 55 & 107.7 & 14.38 & 2.31 & 2.8 & 5.75 & -19 & 24 \\
\hline 56 & 108.3 & 17.84 & 1.48 & 2.9 & 5.91 & -52 & 18 \\
\hline 57 & 108.9 & 12.00 & 1.19 & 2.6 & 5.81 & -91 & 56 \\
\hline 58 & 109.5 & 17.47 & 1.24 & 2.9 & 6.02 & -46 & 19 \\
\hline 59 & 110.1 & 12.55 & 3.16 & 3.0 & 5.90 & -9 & 23 \\
\hline 60 & 110.7 & 14.25 & 0.76 & 2.6 & 5.62 & 37 & 33 \\
\hline 61 & 111.3 & 13.06 & 1.93 & 3.0 & 5.82 & 23 & 3 \\
\hline 62 & 111.9 & 17.49 & 1.50 & 3.0 & 6.09 & -25 & 54 \\
\hline 63 & 112.5 & 13.48 & 1.95 & 2.6 & 5.85 & -2 & -3 \\
\hline 64 & 113.1 & 16.26 & 1.77 & 2.7 & 5.44 & -59 & 11 \\
\hline 65 & 113.7 & 13.05 & 2.69 & 2.6 & 5.41 & -50 & -2 \\
\hline 66 & 114.3 & 15.99 & 1.51 & 2.9 & 5.91 & -112 & 10 \\
\hline 67 & 114.9 & 15.14 & 1.59 & 2.8 & 5.92 & -34 & -19 \\
\hline 68 & 115.5 & 19.60 & 2.16 & 3.3 & 7.07 & -96 & 51 \\
\hline 69 & 116.1 & 17.99 & 1.03 & 3.1 & 6.52 & 81 & 5 \\
\hline 70 & 116.7 & 17.54 & 0.87 & 3.0 & 6.51 & 232 & 24 \\
\hline 71 & 117.3 & 11.75 & 3.58 & 3.2 & 7.27 & 217 & 69 \\
\hline 72 & 117.9 & 13.63 & 3.58 & 2.8 & 6.98 & 190 & 59 \\
\hline 73 & 118.5 & 10.61 & 4.71 & 3.3 & 8.04 & 178 & 53 \\
\hline 74 & 119.1 & 14.72 & 4.06 & 3.1 & 7.02 & 181 & 46 \\
\hline 75 & 119.7 & 9.42 & 5.09 & 3.0 & 7.27 & 175 & 53 \\
\hline 76 & 120.3 & 11.19 & 5.55 & 2.8 & 6.41 & 208 & 52 \\
\hline 77 & 120.9 & 22.70 & 6.44 & 4.0 & 6.60 & 236 & 57 \\
\hline 78 & 121.5 & 14.64 & 4.76 & 3.3 & 7.68 & 140 & 47 \\
\hline 79 & 122.1 & 7.54 & 6.28 & 2.9 & 6.68 & 157 & 62 \\
\hline 80 & 122.7 & 14.51 & 5.68 & 3.2 & 7.04 & 219 & 75 \\
\hline 81 & 123.3 & 8.19 & 5.73 & 2.8 & 6.30 & 164 & 61 \\
\hline 82 & 123.9 & 13.94 & 4.81 & 2.8 & 6.40 & 164 & 42 \\
\hline 83 & 124.5 & 11.12 & 3.61 & 3.3 & 7.09 & & \\
\hline
\end{tabular}

Notes: Section $\mathrm{Cl}=$ Section $135-837 \mathrm{~A}-3 \mathrm{H}-5$; latitude $=20.22^{\circ} \mathrm{S} ;$ longitude $=176.82^{\circ} \mathrm{W}$; water depth $=2752 \mathrm{~m}$. Dark brown clayey nannofossil ooze. $\mathrm{J}_{0}$ is NRM intensity, $\mathrm{J}_{10}$ is intensity after AF-cleaning at $10 \mathrm{mT}$; SIRM = saturated isothermal remanent magnetization after pulse magnetization at $1.2 \mathrm{~T} ; \mathrm{D} 1234$ and $\mathrm{I1} 234$ are the declination and inclination means of $10,20,30$, and $40 \mathrm{mT}$ AF demagnetizations. D1234 is rotated $-160^{\circ}$ with respect to the surface of the split core. 

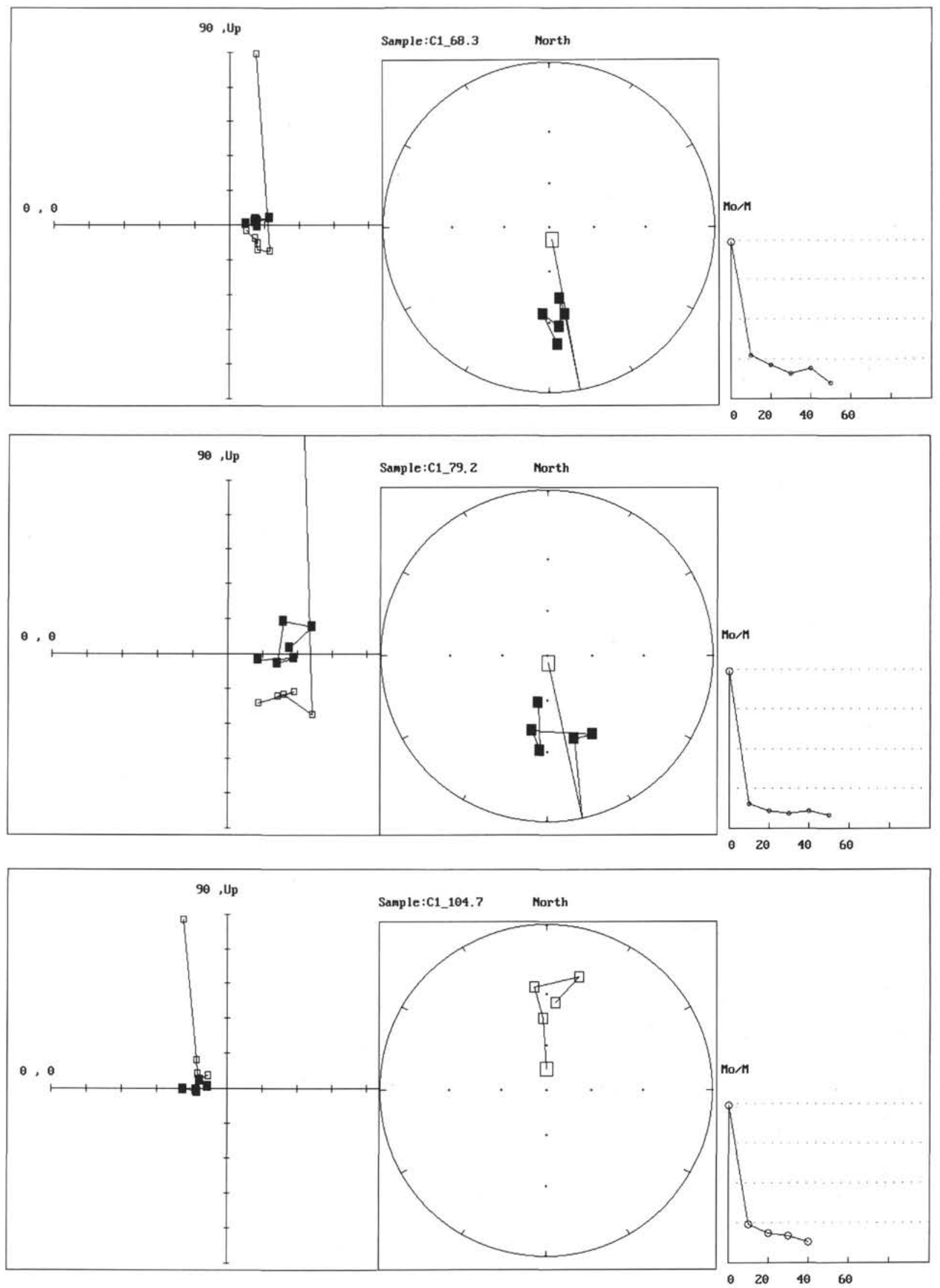

Figure 4. Orthogonal plots on the left, stereograms at center (solid/open symbols indicate positive/negative inclinations), and intensity decay curves on the right (scale in $\mathrm{mT}$ ) for AF demagnetization of three characteristic nannofossil ooze samples from Section C1. NRM intensities are given in Table 2. 


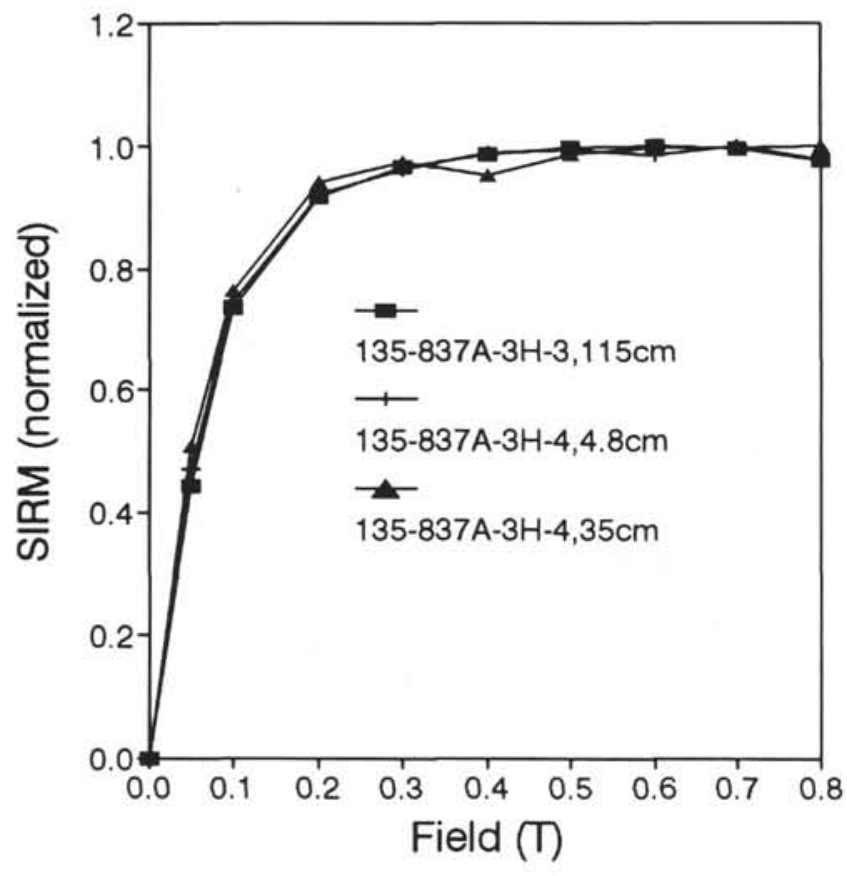

Figure 5. Saturation isothermal remanent magnetization (SIRM) acquisition curves for typical nannofossil ooze samples from Section C1.

$\mathrm{cm}$. The inclination record is more complicated. From a high level $\left(\sim 50^{\circ}\right.$ to $\left.60^{\circ}\right)$ at $118 \mathrm{~cm}$, it fluctuates while gradually decreasing to $-45^{\circ}$ at $90 \mathrm{~cm}$; between 90 and $83 \mathrm{~cm}$ it is close to the geocentric axial dipole value of $-36^{\circ}$; then, between 83 and $75 \mathrm{~cm}$, the reversed level is rapidly restored by means of (noisy?) oscillations. Although declination at both transitions changes rapidly, inclination and intensity $\left(J_{10} /\right.$ SIRM and $Q_{10}$ in Fig. 3 ) seem to be more reluctant in recovering to nontransitional levels.

To smooth the apparent pole position curve without losing too much short-wave information, a five-point moving average (weights $1 / 2+1$ $+1+1+1 / 2$ ) was applied to both declination and inclination separately, as shown in Figure 7. Noise has been significantly suppressed, but short undulations over three or more samples are still retained.

\section{Magnetic Results from Section C2}

Rock magnetic results vs. depth from Cobb Mountain Section C2 are compiled in Figure 8 . The susceptibility and J/SIRM ratio do not show strong trends with depth, but rather the fluctuations appear to indicate fluctuations in magnetic mineralogy, concentration, and grain size as well as experimental noise; hence, we see only minor magnetomineralogical variations with depth. In contrast to this, the normalized ratio $J_{10} /$ SIRM (and also $Q_{10}$ ) shows strongly reduced values around 131 and $96 \mathrm{~cm}$, which correlates well with the two polarity transitions at 129 and $98-99 \mathrm{~cm}$ (see below). At the two low levels of the $J_{10} / \mathrm{SIRM}$ ratio (heavy line), the geomagnetic field was thus reduced to about $20 \%$ of its normal strength (supposed to be the high level of the $J_{10} / \mathrm{SIRM}$ ratio outside the transition parts).

Figure 9 illustrates characteristic examples of individual sample behavior during AF demagnetization. Typically, after $10 \mathrm{mT}$ the direction of the remanence is stabilized, and with further demagnetization a unidirectional reduction of intensity can be observed. The rapid decay of AF-demagnetized intensity (with $\mathrm{MDF}=5-6 \mathrm{mT}$ ), as well as saturation occurring around $0.3 \mathrm{~T}$ in the SIRM acquisition curves (Fig. 10), indicates that the dominant carrier of the remanence is finegrained magnetite.

The directional results of the AF demagnetization at 10,20,30, and $40 \mathrm{mT}$ are shown in Figure 11 for all specimens in Section C2.
Again, adopting the mean for the four demagnetization levels mentioned as the best estimate of the primary magnetization, this mean for each specimen is shown by the bold line. The declination has been rotated $+60^{\circ}$ according to the mean of the nontransitional (dipolar) part of the section. Sample measurements are listed in Table 3.

The declination shows a noisier and also more gradual older R-N polarity transition at the base $(128 \mathrm{~cm})$ than in Section $\mathrm{C} 1$, and also a more gradual young N-R transition at the top $(98 \mathrm{~cm})$. Short-wave variations between $125-118$ and $109-100 \mathrm{~cm}$ are also observed. Inclination shows a similar trend as for Section $\mathrm{C1}$. From a high level $\left(\sim 30^{\circ}\right.$ to $\left.40^{\circ}\right)$ at $130 \mathrm{~cm}$, inclination fluctuates while gradually decreasing to $-45^{\circ}$ at $107 \mathrm{~cm}$; between 107 and $102 \mathrm{~cm}$, it is stable around $-40^{\circ}$; then, between 102 and $92 \mathrm{~cm}$, the reversed level is gradually reached in a series of swings. Inclination and intensity $\left(J_{10} /\right.$ SIRM and $Q_{10}$ in Fig. 8) seem to be more reluctant in recovering to nontransitional levels than does declination.

In Figure 12, five-point moving averages of declination and inclination are shown as the slightly smoothed, heavy curves. Although noise has been significantly suppressed, short undulations over three or more samples are retained.

\section{Magnetic Results from Section C3}

Rock magnetic results vs. depth from Cobb Mountain Section C3 are compiled in Figure 13. The susceptibility shows a decrease of about $30 \%$ between 79 and $70 \mathrm{~cm}$, whereas the levels of the $Q$-ratio and the J/SIRM ratio appear stable. In contrast, the $J_{10} /$ SIRM ratio (and also the $Q_{10}$ ratio) shows strongly reduced values between $91-73$ $\mathrm{cm}$ and $51-45 \mathrm{~cm}$, which correlates with the two polarity transitions at 80 and $51 \mathrm{~cm}$ (see later). Judging from the two low levels of the $J_{10}$ /SIRM ratio (heavy line), the geomagnetic field appears to have been reduced to between $20 \%$ and $30 \%$ of its normal values.

Figure 14 illustrates characteristic examples of individual sample behavior during the AF demagnetization. After $10 \mathrm{mT}$ the direction of the remanence is stabilized, and by further demagnetization a unidirectional reduction toward the origin can be observed. Again, the rapid decay of intensity during $\mathrm{AF}$ demagnetization (with $\mathrm{MDF}=$ $5-6 \mathrm{mT}$ ), as well as the saturation occurring in the SIRM acquisition curves between 0.3 and $0.4 \mathrm{~T}$ (Fig. 15), indicates that the dominant carrier of the remanence is fine-grained magnetite. Details for each sample are listed in Table 4.

The directional results of the AF demagnetization in 10,20,30, and $40 \mathrm{mT}$ are shown in Figure 16 for all specimens in Section C3. As before, the average of the four levels for each specimen is again adopted as the best estimate of the primary remanence, which is shown by the bold line. The declination has been rotated $+125^{\circ}$ according to the mean of the nontransitional (dipolar) part of the section.

The declination of Section $\mathrm{C} 3$ shows a sharp older (R-N) polarity transition at the base $(80 \mathrm{~cm})$, as in Section $\mathrm{Cl}$, and also a more gradual young (N-R) change at the top $(52-50 \mathrm{~cm})$, with an "overshoot" between 50 and $45 \mathrm{~cm}$. In the normal-polarity interval, between 79 and $51 \mathrm{~cm}$, there is little variation in declination. The inclination values display a trend similar to those of Sections $\mathrm{C} 1$ and $\mathrm{C} 2$. From a positive level $\left(\sim 15^{\circ}\right.$ to $\left.30^{\circ}\right)$ at $80 \mathrm{~cm}$, inclination fluctuates while gradually decreasing to $-50^{\circ}$ at $62 \mathrm{~cm}$; between 62 and $47 \mathrm{~cm}$, it varies between -20 and $-60^{\circ}$; and at $46 \mathrm{~cm}$ the inclination changes sharply to positive values. Again, inclination and intensity $\left(J_{10} /\right.$ SIRM and $Q_{10}$ in Fig. 13) seem to be more reluctant than declination in the recovering phase before reaching nontransitional levels. In Figure 17, the directional parameters are again shown with five-point moving averages.

\section{TRANSITIONAL VIRTUAL GEOMAGNETIC POLES: COMPARISONS AND DISCUSSION}

Based on the smoothed values given in Figure 7, the VGP positions may be calculated for Section C1 (Fig. 18), if one assumes that the 
Table 3. Detailed magnetic information for each specimen in Section C2.

\begin{tabular}{|c|c|c|c|c|c|c|c|}
\hline $\begin{array}{c}\text { Sample } \\
\text { no. }\end{array}$ & $\begin{array}{c}\text { Depth } \\
+20.7 \mathrm{~m} \\
(\mathrm{~cm})\end{array}$ & $\begin{array}{c}J_{0} \\
(\mathrm{~mA} / \mathrm{m})\end{array}$ & $\begin{array}{c}J_{10} \\
(\mathrm{~mA} / \mathrm{m})\end{array}$ & $\begin{array}{l}\text { Susceptibility } \\
(\mathrm{cgs}) \times 10^{-5}\end{array}$ & $\begin{array}{l}\text { SIRM } \\
(\mathrm{A} / \mathrm{m})\end{array}$ & $\begin{array}{l}\text { D1234 } \\
\left(+60^{\circ}\right)\end{array}$ & 1123 \\
\hline 1 & 80.0 & 36.53 & 8.38 & 3.5 & 6.20 & 183 & 39 \\
\hline 2 & 80.6 & 37.12 & 9.74 & 3.3 & 6.04 & 177 & 21 \\
\hline 3 & 81.2 & 24.11 & 8.17 & 3.1 & 6.03 & 191 & 37 \\
\hline 4 & 81.8 & 35.61 & 7.79 & 3.3 & 6.33 & 173 & 33 \\
\hline 5 & 82.4 & 28.13 & 8.88 & 3.4 & 6.96 & 173 & 34 \\
\hline 6 & 83.0 & 36.78 & 7.06 & 3.2 & 6.56 & 182 & 35 \\
\hline 7 & 83.6 & 24.95 & 6.47 & 3.2 & 6.61 & 176 & 30 \\
\hline 8 & 84.2 & 40.50 & 5.96 & 3.3 & 6.03 & 181 & 37 \\
\hline 9 & 84.8 & 23.13 & 7.22 & 3.3 & 6.13 & 177 & 29 \\
\hline 10 & 85.4 & 34.85 & 5.39 & 3.4 & 6.01 & 170 & 21 \\
\hline 11 & 86.0 & 28.96 & 7.36 & 3.4 & 6.38 & 160 & 30 \\
\hline 12 & 86.6 & 37.15 & 7.43 & 3.1 & & & \\
\hline 13 & 87.2 & 37.56 & 10.00 & 3.8 & 6.35 & 183 & 18 \\
\hline 14 & 87.8 & 78.46 & 6.49 & 4.5 & 6.64 & 89 & 26 \\
\hline 15 & 88.4 & 26-98 & 4.39 & 3.3 & 6.19 & 193 & 29 \\
\hline 16 & 89.0 & 37.29 & 5.45 & 3.7 & 6.82 & 179 & 29 \\
\hline 17 & 89.61 & 28.47 & 4.01 & 3.6 & 6.68 & 185 & 36 \\
\hline 18 & 90.2 & 35.06 & 3.46 & 3.5 & 7.08 & 185 & 32 \\
\hline 19 & 90.8 & 30.65 & 3.61 & 3.6 & 6.79 & 186 & 15 \\
\hline 20 & 91.4 & 30.62 & 3.35 & 3.3 & 7.07 & 198 & 30 \\
\hline 21 & 92.0 & 33.06 & 4.70 & 3.6 & 6.92 & 186 & 31 \\
\hline 22 & 92.6 & 31.85 & 3.21 & 3.3 & 6.77 & 177 & 27 \\
\hline 23 & 93.2 & 23.66 & 3.78 & 3.3 & 6.65 & 192 & 18 \\
\hline 24 & 93.8 & 25.87 & 2.17 & 3.2 & 5.64 & 196 & 4 \\
\hline 25 & 94.4 & 19.77 & 2.10 & 2.9 & 6.33 & 132 & 47 \\
\hline 26 & 95.0 & 30.62 & 1.43 & 3.0 & 5.91 & 158 & -10 \\
\hline 27 & 95.6 & 28.00 & 2.45 & 3.1 & 6.23 & 187 & 34 \\
\hline 28 & 96.2 & 34.50 & 1.43 & 3.3 & 6.39 & 155 & 8 \\
\hline 29 & 96.8 & 31.79 & 2.67 & 3.2 & 6.32 & 199 & 239 \\
\hline 30 & 97.4 & 40.75 & 2.64 & 3.2 & 6.34 & 153 & -5 \\
\hline 31 & 98.0 & 27.05 & 2.34 & 3.0 & 6.28 & 177 & 13 \\
\hline 32 & 98.6 & 36.13 & 2.87 & 3.1 & 6.43 & 92 & -48 \\
\hline 33 & 99.2 & 44.27 & 4.66 & 3.5 & 6.46 & 48 & -47 \\
\hline 34 & 99.8 & 46.93 & 4.26 & 3.5 & 6.33 & -5 & -39 \\
\hline 35 & 100.4 & 34.02 & 3.02 & 3.1 & 5.93 & 42 & -30 \\
\hline 36 & 101.0 & 35.76 & 9.33 & 3.2 & 6.52 & -43 & 33 \\
\hline 37 & 101.6 & 33.85 & 3.09 & 3.2 & 7.01 & -106 & -44 \\
\hline 38 & 102.2 & 30.35 & 4.85 & 2.9 & 6.14 & -1 & -28 \\
\hline 39 & 102.8 & 25.08 & 4.27 & 2.8 & 7.23 & 23 & -36 \\
\hline 40 & 103.4 & 30.99 & 6.93 & 2.7 & 7.23 & 23 & -36 \\
\hline 41 & 104.0 & 26.31 & 5.68 & 2.8 & 5.56 & -53 & -40 \\
\hline 42 & 104.6 & 44.81 & 7.23 & 3.5 & 6.98 & -44 & -39 \\
\hline 43 & 105.2 & 26.31 & 4.08 & 2.9 & 5.47 & -43 & -45 \\
\hline 44 & 105.8 & 27.85 & 4.60 & 2.7 & 5.35 & -52 & -42 \\
\hline 45 & 106.4 & 21.15 & 3.83 & 2.5 & 5.00 & -64 & -40 \\
\hline 46 & 107.0 & 31.44 & 5.15 & 2.7 & 5.44 & -58 & -40 \\
\hline 47 & 107.6 & 22.89 & 3.27 & 2.7 & 5.45 & -157 & -10 \\
\hline 48 & 108.2 & 27.36 & 2.99 & 2.7 & 4.99 & -67 & -30 \\
\hline 49 & 108.8 & 25.29 & 4.73 & 2.8 & 5.27 & 2 & -10 \\
\hline 50 & 109.4 & 25.10 & 6.81 & 2.8 & 5.02 & 21 & -35 \\
\hline 51 & 110.0 & 22.04 & 4.36 & 2.6 & 5.15 & 27 & -44 \\
\hline 52 & 110.6 & 34.12 & 4.97 & 3.2 & 5.17 & 0 & -38 \\
\hline 53 & 111.2 & 23.94 & 5.21 & 2.8 & 5.10 & 16 & -22 \\
\hline 54 & 111.8 & 26.54 & 4.99 & 2.6 & 5.08 & -4 & -23 \\
\hline 55 & 112.4 & 23.38 & 4.59 & 2.7 & 5.36 & -25 & -24 \\
\hline 56 & 113.0 & 27.56 & 3.87 & 2.8 & 5.19 & -17 & -13 \\
\hline
\end{tabular}

\begin{tabular}{|c|c|c|c|c|c|c|c|}
\hline $\begin{array}{l}\text { Sample } \\
\text { no. }\end{array}$ & $\begin{array}{c}\text { Depth } \\
+20.7 \mathrm{~m} \\
(\mathrm{~cm})\end{array}$ & $\begin{array}{c}J_{0} \\
(\mathrm{~mA} / \mathrm{m})\end{array}$ & $\begin{array}{c}J_{10} \\
(\mathrm{~mA} / \mathrm{m})\end{array}$ & $\begin{array}{l}\text { Susceptibility } \\
(\mathrm{cgs}) \times 10^{-5}\end{array}$ & $\begin{array}{l}\text { SIRM } \\
(\mathrm{A} / \mathrm{m})\end{array}$ & $\begin{array}{l}\text { D1234 } \\
\left(+60^{\circ}\right)\end{array}$ & 1123 \\
\hline 57 & 113.6 & 23.20 & 2.99 & 2.5 & 5.20 & 19 & -20 \\
\hline 58 & 114.2 & 23.00 & 3.08 & 2.4 & 5.19 & 7 & -12 \\
\hline 59 & 114.8 & 21.82 & 3.88 & 2.6 & 5.13 & 1 & -33 \\
\hline 60 & 115.4 & 40.63 & 2.83 & 3.2 & 5.45 & 4 & -18 \\
\hline 61 & 116.0 & 24.20 & 4.59 & 3.0 & 5.38 & 41 & -17 \\
\hline 62 & 116.6 & 29.59 & 2.54 & 3.0 & 5.28 & 34 & -32 \\
\hline 63 & 117.2 & 34.51 & 5.48 & 3.0 & 5.41 & 5 & -17 \\
\hline 64 & 117.8 & 26.64 & 1.33 & 3.3 & 5.23 & -56 & 8 \\
\hline 65 & 118.4 & 21.87 & 2.04 & 2.8 & 5.53 & 35 & -13 \\
\hline 66 & 119.0 & 25.88 & 2.91 & 3.0 & 5.44 & 13 & -12 \\
\hline 67 & 119.6 & 29.20 & 2.16 & 3.2 & 5.85 & 19 & 28 \\
\hline 68 & 120.2 & 23.52 & 2.53 & 2.8 & 5.20 & -2 & 1 \\
\hline 69 & 120.8 & 22.70 & 2.26 & 2.9 & 5.41 & 28 & -17 \\
\hline 70 & 121.4 & 25.30 & 2.53 & 2.9 & 5.34 & 68 & -15 \\
\hline 71 & 122.0 & 22.94 & 3.65 & 3.0 & 5.82 & 84 & 30 \\
\hline 72 & 122.6 & 33.81 & 1.51 & 3.6 & 6.14 & -131 & 5 \\
\hline 73 & 123.2 & 25.04 & 2.39 & 3.2 & 5.98 & -13 & 25 \\
\hline 74 & 123.8 & 29.28 & 1.57 & 3.3 & 6.22 & -74 & -5 \\
\hline 75 & 124.4 & 29.49 & 3.92 & 3.5 & 6.12 & 7 & -11 \\
\hline 76 & 125.0 & 29.46 & 0.94 & 3.3 & 6.39 & -83 & 58 \\
\hline 77 & 125.6 & 34.18 & 4.10 & 3.7 & 6.64 & 87 & 11 \\
\hline 78 & 126.2 & 26.83 & 1.05 & 3.1 & 6.23 & 21 & -17 \\
\hline 79 & 126.8 & 18.83 & 1.97 & 2.9 & 5.40 & 47 & -5 \\
\hline 80 & 127.4 & 41.51 & 1.72 & 3.9 & 6.71 & 154 & -6 \\
\hline 81 & 128.0 & 32.40 & 3.17 & 3.7 & 6.92 & 9 & -47 \\
\hline 82 & 128.6 & 35.89 & 1.63 & 3.7 & 7.16 & 146 & 39 \\
\hline 83 & 129.8 & 29.59 & 1.73 & 3.7 & 7.41 & 117 & 30 \\
\hline 84 & 129.8 & 46.53 & 1.01 & 3.6 & 7.18 & 37 & 2 \\
\hline 85 & 130.4 & 32.70 & 1.84 & 3.6 & 7.17 & 126 & 45 \\
\hline 86 & 131.0 & 35.45 & 1.47 & 3.9 & 7.53 & 216 & 26 \\
\hline 87 & 131.6 & 26.10 & 0.70 & 3.6 & 7.47 & 233 & 27 \\
\hline 88 & 132.2 & 30.64 & 1.66 & 3.5 & 7.07 & 234 & 6 \\
\hline 89 & 132.8 & 27.85 & 2.45 & 3.8 & 7.41 & 223 & 16 \\
\hline 90 & 133.4 & 35.33 & 1.69 & 4.3 & 8.46 & 186 & 25 \\
\hline 91 & 134.0 & 33.52 & 4.18 & 4.4 & 8.80 & 182 & 64 \\
\hline 92 & 134.6 & 32.47 & 1.68 & 4.0 & 8.62 & 174 & 41 \\
\hline 93 & 135.2 & 23.65 & 4.60 & 3.9 & 8.73 & 203 & 35 \\
\hline 94 & 135.8 & 27.69 & 3.35 & 4.2 & 8.42 & 232 & 35 \\
\hline 95 & 136.4 & 28.37 & 2.33 & 3.8 & 7.62 & 189 & 31 \\
\hline 96 & 137.0 & 29.27 & 2.55 & 4.0 & 9.06 & 189 & 14 \\
\hline 97 & 137.6 & 24.98 & 6.27 & 4.2 & 8.65 & 198 & 27 \\
\hline 98 & 138.2 & 28.79 & 5.66 & 4.3 & 8.53 & 201 & 27 \\
\hline 99 & 138.8 & 26.39 & 5.75 & 3.8 & 8.18 & 178 & 55 \\
\hline 100 & 139.4 & 19.83 & 7.73 & 3.4 & 7.67 & 205 & 25 \\
\hline 101 & 140.0 & 17.84 & 6.47 & 3.4 & 8.37 & 207 & 32 \\
\hline 102 & 140.6 & 18.86 & 5.83 & 3.4 & 7.41 & 126 & 47 \\
\hline 103 & 141.2 & 14.62 & 5.24 & 3.1 & 6.93 & 178 & 44 \\
\hline 104 & 141.8 & 23.54 & 3.01 & 4.0 & 10.20 & -165 & 21 \\
\hline
\end{tabular}

Notes: Section $\mathrm{C} 2=135-838 \mathrm{~A}-3 \mathrm{H}-6$; latitutde $=0.83^{\circ} \mathrm{S}$; longitude $=176.89^{\circ} \mathrm{W}$; water depth $=2323 \mathrm{~m}$. Dark brown clayey nannofossil ooze. $J_{0}$ is NRM intensity, $J_{10}$ is intensity after AF-cleaning at $10 \mathrm{mT}$; SIRM = saturated isothermal remanent magnetization after pulse magnetization at $1.2 \mathrm{~T} ; \mathrm{D} 1234$ and 11234 are the declination and inclination means of $10,20,30$, and $40 \mathrm{mT}$ AF demagnetizations. D1234 is rotated $+160^{\circ}$ with respect to the surface of the split core.

geomagnetic field is equivalent to a central dipole field (e.g., Merrill and McElhinny, 1983). Following the first (old) rapid polarity transition ( $\mathrm{R}$ to $\mathrm{N}$ ), two short-lived loops are seen in the Northern Hemisphere, one of them having the character of a geomagnetic excursion, the latitude going below $60^{\circ}$ (cf. Fig. 7, the two oscillations in declination between 116 and $108 \mathrm{~cm}$ ). The younger transition ( $\mathrm{N}$ to $\mathrm{R}$ ) is more gradual and after the ( $\mathrm{N}$ to $\mathrm{R}$ ) polarity change, the youngest part of the ( $\mathrm{N}$ to $\mathrm{R}$ ) transition also has the character of an excursion because of the "overshoot" in declination (cf. Fig. 7, 82-78 cm). For the old transition ( $\mathrm{R}$ to $\mathrm{N}$ ), the pole-clusters in both hemispheres are "near-sided" (i.e., closer to the sampling site than the north pole of the central axial dipole; Wilson, 1970; Merrill and McElhinny, 1983). The pole clustering after the young polarity transition ( $\mathrm{N}$ to $\mathrm{R}$ ) is "farsided" first and finally ends up as being "near-sided."

In the same manner as above, based on the smoothed values of Figure 12, the virtual pole positions are calculated for Section $\mathrm{C} 2$ and are shown in Figure 19. Following the first (old) rapid polarity transition ( $\mathrm{R}$ to N), as in Section C1, a loop can be seen in the Northern
Hemisphere for Section $\mathrm{C} 2$ that has the character of a geomagnetic excursion, as the latitude goes below $60^{\circ} \mathrm{N}$. In this record both the older ( $\mathrm{R}$ to $\mathrm{N}$ ) and younger ( $\mathrm{N}$ to $\mathrm{R}$ ) transitions are rather gradual, the transitions being recorded by 10 and 5 data points between $\pm 70^{\circ}$, respectively. Before the young ( $\mathrm{N}$ to $\mathrm{R})$ transition begins, still another excursion can be seen in the Northern Hemisphere as an "overshoot" in declination (Fig. 12, 110-104 cm). After the young ( $\mathrm{N}$ to $\mathrm{R}$ ) transition, again the same loop in longitude up to $60^{\circ} \mathrm{E}$ can be seen as in Section $\mathrm{C}$; ; however, because of the higher negative latitude (it does not go north of $60^{\circ} \mathrm{S}$ ), it is not formally a transition. Again, as for Section C1, the Section C2 poles in both hemispheres of the older transition ( $\mathrm{R}$ to $\mathrm{N}$ ) are dominated by "near-sided" poles, whereas the pole-cluster is "far-sided" after the young polarity transition (N to R).

Based on the smoothed values of Figure 17, the virtual pole positions are calculated for Section C3 and shown in Figure 20. In this record also, the older and younger transitions are relatively gradual, as they are shown by 8 and 5 data points between latitude $\pm 70^{\circ}$, respectively. The young part shows the same kind of loop in longitude up to 
Table 4. Detailed magnetic information for each specimen in Section C3.

\begin{tabular}{|c|c|c|c|c|c|c|c|}
\hline $\begin{array}{l}\text { Sample } \\
\text { no. }\end{array}$ & $\begin{array}{l}\text { Depth } \\
+40.5 \mathrm{~m} \\
(\mathrm{~cm})\end{array}$ & $\begin{array}{c}J_{0} \\
(\mathrm{~mA} / \mathrm{m})\end{array}$ & $\begin{array}{c}J_{10} \\
(\mathrm{~mA} / \mathrm{m})\end{array}$ & $\begin{array}{l}\text { Susceptibility } \\
(\mathrm{cgs}) \times 10^{-5}\end{array}$ & $\begin{array}{l}\text { SIRM } \\
(\mathrm{A} / \mathrm{m})\end{array}$ & $\begin{array}{l}\text { D1234 } \\
\left(+125^{\circ}\right)\end{array}$ & I1234 \\
\hline 1 & 30.0 & 13.05 & 7.07 & 2.7 & 5.75 & 173 & 37 \\
\hline 2 & 30.6 & 9.56 & 6.74 & 2.8 & 6.22 & 186 & 40 \\
\hline 3 & 31.2 & 12.97 & 5.30 & 2.6 & 5.59 & 160 & 34 \\
\hline 4 & 31.8 & 10.81 & 5.01 & 2.6 & 5.63 & 170 & 20 \\
\hline 5 & 32.4 & 13.63 & 6.55 & 2.7 & 6.13 & 179 & 27 \\
\hline 6 & 33.0 & 22.65 & 4.29 & 3.2 & 6.13 & 100 & 14 \\
\hline 7 & 33.6 & 17.38 & 6.23 & 3.0 & 6.16 & 194 & 34 \\
\hline 8 & 34.2 & 10.38 & 5.86 & 2.7 & 5.95 & 178 & 31 \\
\hline 9 & 34.8 & 12.43 & 5.56 & 2.9 & 6.15 & 172 & 39 \\
\hline 10 & 35.4 & 10.18 & 4.68 & 2.9 & 5.91 & 180 & 29 \\
\hline 11 & 36.0 & 15.39 & 4.41 & 2.9 & 6.25 & 165 & 33 \\
\hline 12 & 36.6 & 11.24 & 4.22 & 2.9 & 6.17 & 176 & 39 \\
\hline 13 & 37.2 & 18.89 & 3.86 & 3.0 & 6.57 & 179 & 33 \\
\hline 14 & 37.8 & 10.23 & 4.98 & 2.8 & 6.20 & 182 & 37 \\
\hline 15 & 38.4 & 18.26 & 2.73 & 3.0 & 6.53 & 158 & 9 \\
\hline 16 & 39.0 & 12.80 & 3.22 & 3.0 & 6.48 & 171 & 26 \\
\hline 17 & 39.6 & 20.28 & 3.36 & 3.2 & 6.97 & 176 & 7 \\
\hline 18 & 40.2 & 25.72 & 4.91 & 3.6 & 6.53 & 172 & -17 \\
\hline 19 & 40.8 & 16.97 & 4.24 & 3.2 & 6.78 & 184 & 26 \\
\hline 20 & 41.4 & 15.90 & 2.40 & 3.0 & 6.28 & 200 & 14 \\
\hline 21 & 42.0 & 16.45 & 5.37 & 3.0 & 6.86 & 185 & 29 \\
\hline 22 & 42.6 & 13.17 & 4.95 & 2.9 & 6.30 & 170 & 25 \\
\hline 23 & 43.2 & 19.04 & 4.52 & 3.2 & 6.90 & 168 & 35 \\
\hline 24 & 43.8 & 16.56 & 3.58 & 3.0 & 6.38 & 196 & 29 \\
\hline 25 & 46.0 & 18.80 & 1.83 & 2.8 & 6.14 & 160 & 19 \\
\hline 26 & 46.6 & 18.16 & 1.07 & 3.1 & 6.68 & 253 & 14 \\
\hline 27 & 47.2 & 27.03 & 4.30 & 3.2 & 6.76 & 347 & -45 \\
\hline 28 & 47.8 & 20.26 & 2.24 & 3.3 & 6.84 & 153 & -35 \\
\hline 29 & 48.4 & 23.42 & 1.44 & 3.0 & 6.56 & 297 & -54 \\
\hline 30 & 49.0 & 16.14 & 1.04 & 3.1 & 6.56 & 302 & \\
\hline 31 & 49.6 & 24.20 & 1.71 & 3.2 & 6.95 & 216 & -38 \\
\hline 32 & 50.2 & 16.56 & 2.03 & 3.2 & 7.01 & 161 & 1 \\
\hline 33 & 50.8 & 21.01 & 1.90 & 3.0 & 6.54 & 166 & -42 \\
\hline 34 & 51.4 & 24.38 & 4.09 & 3.4 & 7.41 & 51 & -39 \\
\hline 35 & 52.0 & 25.86 & 5.71 & 3.1 & 6.67 & 43 & -39 \\
\hline 36 & 52.6 & 19.30 & 5.74 & 3.0 & 6.28 & -0 & -29 \\
\hline 37 & 53.2 & 24.27 & 5.38 & 3.0 & 6.43 & 20 & -31 \\
\hline 38 & 53.8 & 17.72 & 5.68 & 2.8 & 5.69 & 1 & -22 \\
\hline 39 & 54.4 & 21.12 & 5.14 & 2.9 & 5.73 & I & 3 \\
\hline 40 & 55.0 & 15.57 & 5.11 & 2.7 & 5.74 & 1 & 2 \\
\hline 41 & 55.6 & 19.13 & 4.15 & 2.8 & 5.55 & -16 & -37 \\
\hline 42 & 56.2 & 17.76 & 5.41 & 2.8 & 5.91 & 1 & 8 \\
\hline 43 & 56.8 & 24.17 & 4.47 & 3.0 & 6.17 & 83 & -47 \\
\hline 44 & 57.4 & 15.56 & 3.98 & 2.6 & 5.53 & 25 & -31 \\
\hline 45 & 58.0 & 23.94 & 5.38 & 2.9 & 5.94 & 5 & -29 \\
\hline 46 & 58.6 & 17.40 & 4.57 & 2.8 & 5.81 & 9 & -52 \\
\hline 47 & 59.2 & 25.01 & 6.61 & 3.0 & 6.25 & 5 & -26 \\
\hline 48 & 59.8 & 16.75 & 5.23 & 2.7 & 5.52 & 27 & -32 \\
\hline 49 & 61.0 & 14.15 & 3.19 & 2.6 & 5.54 & -6 & -41 \\
\hline 50 & 62.2 & 14.99 & 3.09 & 2.7 & 5.84 & 11 & -39 \\
\hline 51 & 63.4 & 23.47 & 4.57 & 2.9 & 5.70 & 18 & -36 \\
\hline 52 & 64.6 & 13.32 & 2.86 & 2.6 & 5.52 & 21 & -25 \\
\hline 53 & 66.0 & 13.02 & 2.26 & 2.7 & 5.83 & 30 & -11 \\
\hline 54 & 67.2 & 13.99 & 3.53 & 2.7 & 5.81 & 22 & -11 \\
\hline
\end{tabular}

\begin{tabular}{|c|c|c|c|c|c|c|c|}
\hline $\begin{array}{c}\text { Sample } \\
\text { no. }\end{array}$ & $\begin{array}{c}\text { Depth } \\
+40.5 \mathrm{~m} \\
(\mathrm{~cm})\end{array}$ & $\underset{(\mathrm{mA} / \mathrm{m})}{J_{0}}$ & $\begin{array}{c}J_{10} \\
(\mathrm{~mA} / \mathrm{m})\end{array}$ & $\begin{array}{l}\text { Susceptibility } \\
(\mathrm{cgs}) \times 10^{-5}\end{array}$ & $\begin{array}{l}\text { SIRM } \\
(\mathrm{A} / \mathrm{m})\end{array}$ & $\begin{array}{c}\text { D1234 } \\
\left(+125^{\circ}\right)\end{array}$ & I1 234 \\
\hline 55 & 68.4 & 13.56 & 4.00 & 2.6 & 5.62 & 5 & -36 \\
\hline 56 & 69.6 & 12.56 & 2.91 & 2.6 & 5.79 & 1 & -10 \\
\hline 57 & 70.2 & 15.94 & 3.64 & 2.4 & 5.34 & 2 & -29 \\
\hline 58 & 70.8 & 14.06 & 2.81 & 2.7 & 5.91 & 15 & -26 \\
\hline 59 & 71.4 & 14.94 & 2.76 & 3.0 & 6.35 & 29 & 5 \\
\hline 60 & 72.0 & 25.70 & 2.03 & 2.9 & 5.81 & -12 & 18 \\
\hline 61 & 72.6 & 16.92 & 2.18 & 3.3 & 6.57 & 33 & 6 \\
\hline 62 & 73.2 & 26.58 & 1.21 & 3.2 & 6.55 & 15 & 2 \\
\hline 63 & 74.4 & 28.26 & 1.07 & 3.2 & 6.61 & 57 & -15 \\
\hline 64 & 75.0 & 16.85 & 1.56 & 3.3 & 6.59 & 1 & 10 \\
\hline 65 & 75.6 & 28.13 & 3.31 & 3.3 & 6.90 & 13 & -7 \\
\hline 66 & 76.2 & 16.29 & 1.14 & 3.3 & 6.90 & 19 & 21 \\
\hline 67 & 76.8 & 26.93 & 2.50 & 3.3 & 7.00 & -16 & -21 \\
\hline 68 & 77.4 & 10.92 & 2.25 & 2.3 & 5.24 & -7 & 5 \\
\hline 69 & 78.0 & 18.80 & 1.30 & 2.8 & 6.17 & 49 & 14 \\
\hline 70 & 78.6 & 13.66 & 1.09 & 3.0 & 6.39 & -10 & 14 \\
\hline 71 & 79.2 & 24.97 & 1.83 & 3.4 & 6.87 & 45 & 16 \\
\hline 72 & 79.8 & 18.80 & 2.90 & 4.1 & 7.75 & 108 & 45 \\
\hline 73 & 80.4 & 32.70 & 1.14 & 4.0 & 8.17 & 210 & 10 \\
\hline 74 & 81.0 & 20.66 & 2.00 & 4.0 & 8.05 & 182 & 19 \\
\hline 75 & 82.2 & 20.09 & 2.65 & 4.1 & 7.99 & 175 & 6 \\
\hline 76 & 83.4 & 32.73 & 2.25 & 4.1 & 8.03 & 171 & 18 \\
\hline 77 & 84.0 & 19.69 & 3.52 & 4.0 & 7.74 & 188 & 18 \\
\hline 78 & 84.6 & 32.28 & 1.58 & 4.3 & 8.16 & 159 & 21 \\
\hline 79 & 85.2 & 22.38 & 1.31 & 4.3 & 8.32 & 151 & 13 \\
\hline 80 & 85.8 & 24.61 & 1.27 & 4.2 & 8.45 & 164 & 28 \\
\hline 81 & 86.4 & 20.25 & 2.49 & 4.1 & 8.21 & 161 & 18 \\
\hline 82 & 87.0 & 31.96 & 2.37 & 4.7 & 9.14 & 190 & 11 \\
\hline 83 & 87.6 & 25.00 & 2.20 & 5.1 & 9.46 & 176 & 17 \\
\hline 84 & 88.2 & 42.46 & 1.55 & 5.5 & 9.50 & 259 & 15 \\
\hline 85 & 88.8 & 18.09 & 3.82 & 3.6 & 8.06 & 247 & 34 \\
\hline 86 & 89.4 & 26.73 & 1.82 & 3.9 & 8.17 & 171 & -23 \\
\hline 87 & 90.0 & 18.57 & 2.93 & 3.5 & 7.00 & 165 & 3 \\
\hline 88 & 90.6 & 31.45 & 2.52 & 4.6 & 9.31 & 173 & 17 \\
\hline 89 & 91.2 & 22.36 & 2.00 & 4.9 & 8.94 & 204 & 17 \\
\hline 90 & 91.8 & 36.68 & 3.04 & 4.7 & 8.41 & 201 & -16 \\
\hline 91 & 92.4 & 19.73 & 6.95 & 4.5 & 8.82 & 174 & 16 \\
\hline 92 & 93.0 & 25.44 & 5.31 & 4.3 & 8.62 & 170 & 10 \\
\hline 93 & 93.6 & 25.76 & 5.25 & 4.3 & 8.34 & 183 & 11 \\
\hline 94 & 94.2 & 22.69 & 5.19 & 4.2 & 8.52 & 202 & 32 \\
\hline 95 & 94.8 & 13.29 & 4.38 & 3.8 & 8.29 & 191 & 36 \\
\hline 96 & 95.4 & 18.48 & 3.98 & 3.9 & 8.80 & 213 & 20 \\
\hline
\end{tabular}

Notes: Section C3 $=135-839 \mathrm{~A}-5 \mathrm{H}-6$; latitude $=20.71^{\circ} \mathrm{S}$; longitude $=176.78^{\circ} \mathrm{W}$; water depth $=2617 \mathrm{~m}$. Dark brown clayey nannofossil ooze. $J_{0}$ is NRM intensity, $J_{10}$ is intensity after AF-cleaning at $10 \mathrm{mT}$ : SIRM = saturated isothermal remanent magnetization after pulse magnetization at $1.2 \mathrm{~T} ; \mathrm{D} 1234$ and I1234 are the declination and inclination means of 10,20,30, and $40 \mathrm{mT}$ AF demagnetizations. D1234 is rotated $+125^{\circ}$ with respect to the surface of the split core.

$80^{\circ} \mathrm{E}$, and has the character of an excursion. Again, as for Sections $\mathrm{C} 1$ and $\mathrm{C} 2$, for Section $\mathrm{C} 3$ the pole clusters in both hemispheres before and after the old transition ( $\mathrm{R}$ to $\mathrm{N}$ ) are "near-sided," whereas the poles are "far-sided" after the young polarity transition (N to R).

The transition times required for the field to switch from one polarity to the other may be estimated either from the number of intermediate virtual pole positions (in Figs. 18-20), or from the drop in apparent geomagnetic field intensity as estimated from the $J_{10} / S I R M$ and $Q_{10}$ ratios (in Figs. 3, 8, and 13). Counting the number of VGPs situated between latitude $\pm 70^{\circ}$, the transition times thus appear to have been between 1.0 and $1.5 \mathrm{k} . \mathrm{y}$., whereas the average transition time, estimated from the drop in intensity to below $33 \%$ of the normal value, was only about $0.6 \mathrm{k} . y$., applying the deposition rates from Table 1. It should also be noted that the initial decay times for both transitions, (Figs. 3,8, and 13) appear to be shorter (about 2-4 times) than the duration of the recovery phase.

Because of the smoothing of the VGPs, the transition time estimates based on the VGPs may be slightly high. We conclude, therefore, that the Cobb Mountain transition times for effectively switching over the field appears to have been very short, indeed, on the order of some 0.6 and 1.0 k.y. only.

All three records of the Cobb Mountain Event, measured from cores in close proximity to one another (intersite distances were less than $0.5^{\circ}$ ), show the same major trends with respect to near-sidedand far-sidedness, suggesting that these features are real and caused by an axial geomagnetic shift (Wilson, 1970) rather than by sediment compaction or refraction effects (Arason and Levi, 1990a, 1990b; Gordon, 1990; Abrahamsen, 1992). Furthermore, the transitional VGPs of our records are situated in approximately the same girdles. The old ( $\mathrm{R}$ to $\mathrm{N}$ ) transition poles follow an azimuthally "oblique" path, crossing meridians from longitude $90^{\circ} \mathrm{W} \pm 10^{\circ}$ to longitude $160^{\circ} \mathrm{W} \pm 10^{\circ}$, whereas the young ( $\mathrm{N}$ to $\mathrm{R}$ ) transition poles follow an azimuthally oblique, subparallel path shifted in longitude some $30^{\circ} \pm$ $10^{\circ}$ to the east, as compared with the old ( $\mathrm{R}$ to $\mathrm{N}$ ) transition.

This approximate trend along the Americas has recently been ascribed as a common feature also for the Matuyama-Brunhes, the Olduvai, and the Blake transitional VGPs (Tric et al., 1991), which may indicate a persistent transitional field behavior perhaps related to core-mantle boundary topography and/or to lithospheric structures (Laj et al., 1991; Tric et al., 1991).

In contrast, the two Cobb Mountain records of Clement (1992) and Clement and Martinson (1992) from the Labrador and North 

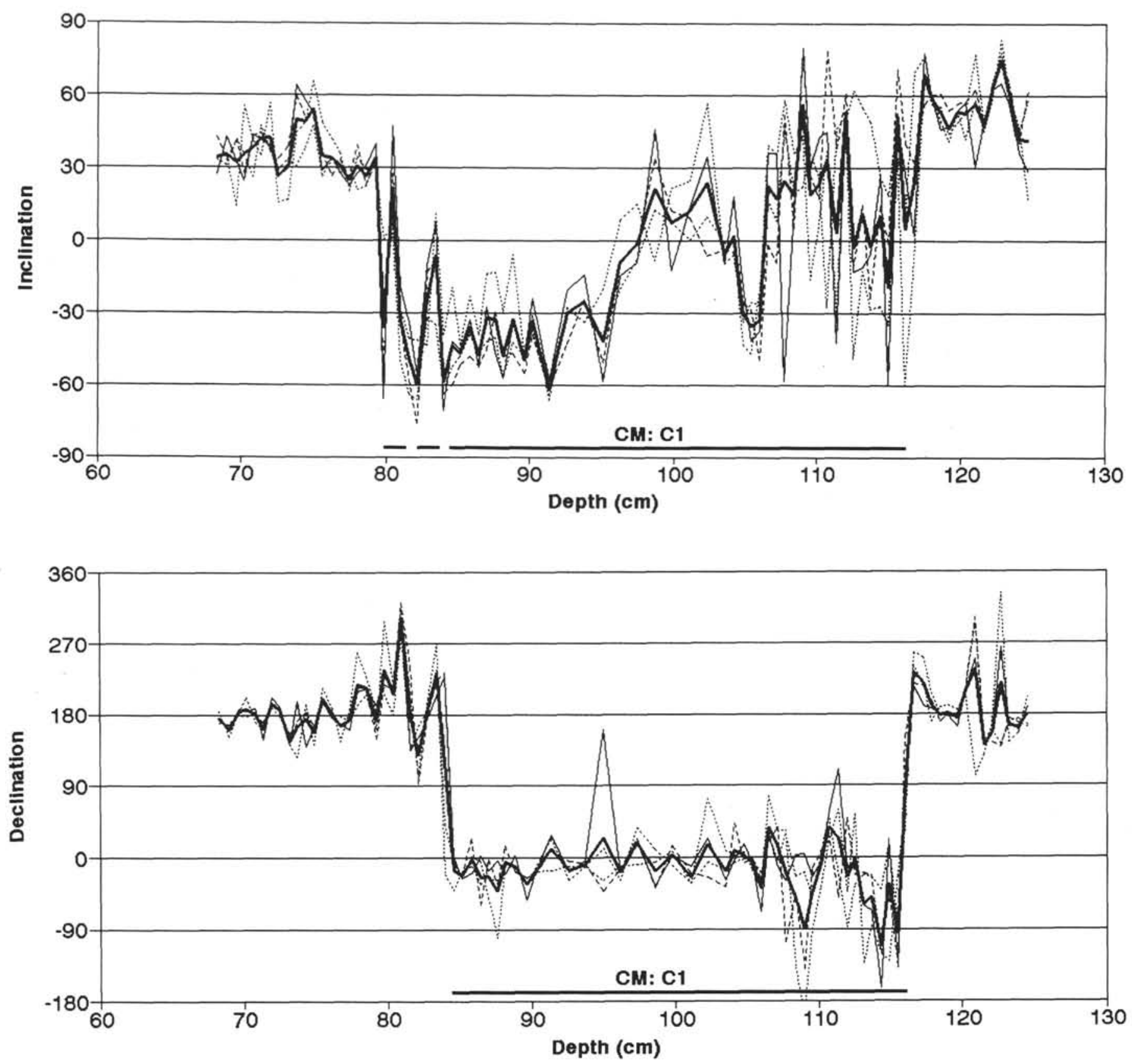

Figure 6. Declination and inclination records of Section $\mathrm{Cl}$ after AF demagnetization at 10, 20,30, and $40 \mathrm{mT}$. Bold line is the average of the four levels. The end of Section $\mathrm{C} 1$ occurs at $84 \mathrm{~cm}$ in the declination plot, but at $80 \mathrm{~cm}$ in inclination plot (dashed line).

Atlantic do not follow this girdle, whereas our data show roughly the same VGPs as records from the Celebes and Sulu seas (Hsu et al., 1990 ), provided that these data are translated longitudinally $60^{\circ}$ to the east, equivalent to the latitudinal difference between the sites. Also, the "inclination-rebound" feature at the end of the Cobb Mountain Event is not as clearly seen in our records as it is in the North Atlantic cores, suggesting that some of the features are not global.

The simplest explanation of these features is that the Cobb Mountain reversal transition records (and other transitions, too) taking place at strongly reduced geomagnetic field strengths are highly sensitive to nonaxial field components of local rather than regional or global extent (i.e., equivalent to high-order spherical harmonics). Therefore, they may appear different when recorded at different sites on the globe, even though all the sections basically have recorded the same, truly global geomagnetic event.

\section{CONCLUSIONS}

We may conclude that (1) the transition times for the Cobb Mountain geomagnetic polarity event, as seen in the three Lau Basin sediment records, appear to have been as short as 0.6-1.0 k.y.; (2) the duration of the normal-polarity event itself lasted only about $17 \pm 4$ k.y.; (3) both the older ( $R$ to $N$ ) and younger ( $N$ to $R$ ) transitions show VGP paths roughly along the Americas, but the latter have been shifted 

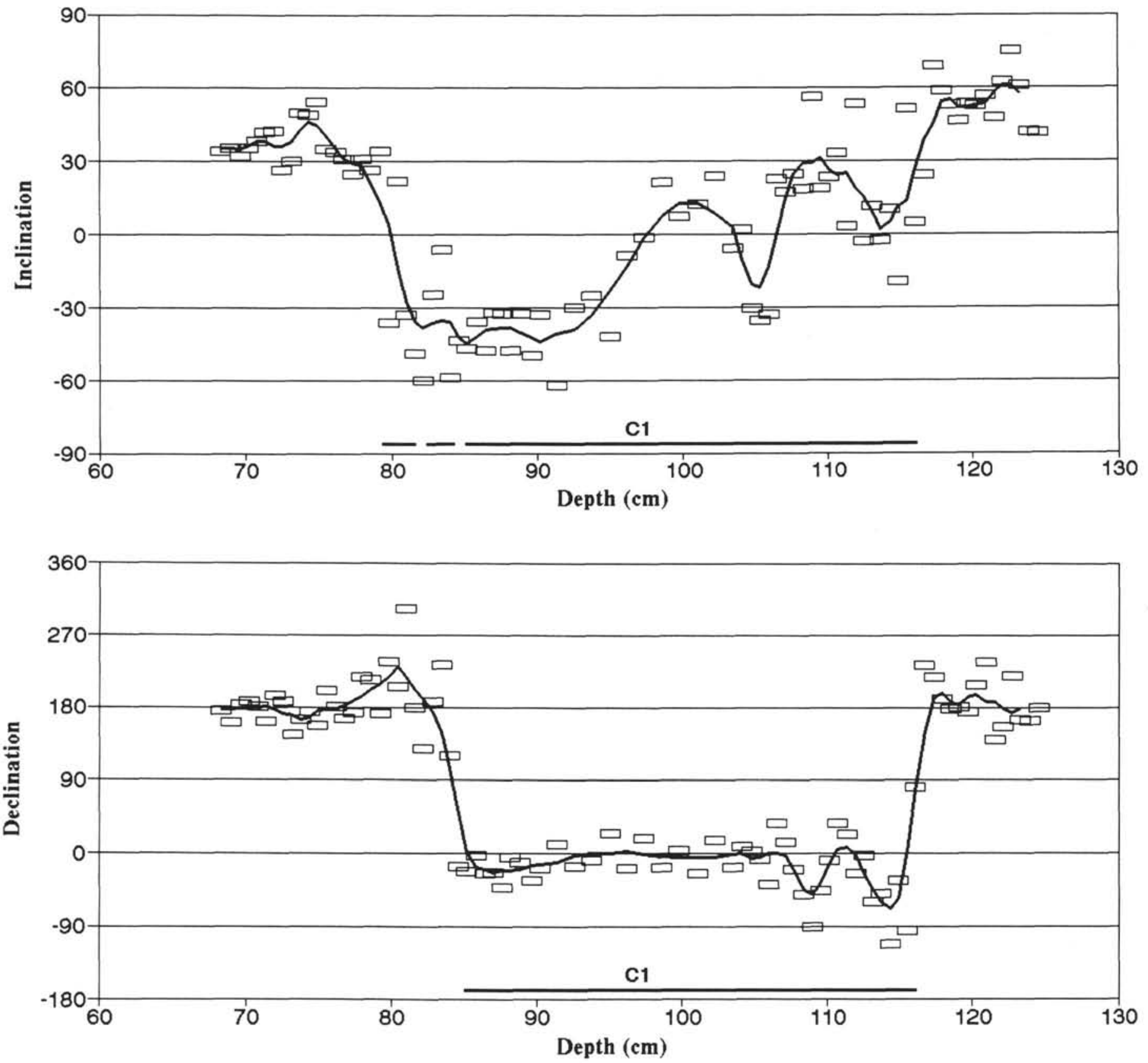

Figure 7. Smoothed declination and inclination of Section C1. Open symbols = average (at 10, 20, 30, and $40 \mathrm{mT}$; cf. Table 2) for each sample (the full line in Fig. 6). Solid curve = running mean through a window with weights $1 / 2+1+1+1+1 / 2$.

$30^{\circ} \pm 10^{\circ}$ to the east; and, (4) although these VGP paths are different from those from the Labrador Sea and the North Atlantic, they are in fair agreement with those from the Celebes and Sulu seas and, when corrected for differences in site longitude, suggest that the transitional fields are dominated by nonaxial, high-order spherical harmonics.

\section{ACKNOWLEDGMENTS}

Part of the work was supported by a grant to N. Abrahamsen from the Danish Natural Science Foundation and to W.W. Sager by JOI/ USSAC. We thank Evelyn Polgreen Myers for assistance in making measurements.

\section{REFERENCES}

Abrahamsen, N., 1992. On farsidedness of palaeomagnetic poles: magnetic refraction, sediment compaction and dipole off-set. Stud. Geophys. Geod., 36:26-41.

Arason, P., and Levi, S., 1990a. Compaction and inclination shallowing in deep-sea sediments from the Pacific Ocean. J. Geophys. Res., 95:45014510.

\footnotetext{
"Abbreviations for names of organizations and publication titles in ODP reference lists follow the style given in Chemical Abstracts Service Source Index (published by American Chemical Society).
} 
1990b. Models of inclination shallowing during sediment compaction. J. Geophys. Res., 95:4481-4500.

Champion, D.E., Lamphere, M.A., and Kuntz, M.A., 1988. Evidence for a new geomagnetic reversal from lava flows in Idaho: discussion of short polarity reversals in the Brunhes and Late Matuyama polarity chrons. J. Geophys. Res., 93:11667-11681.

Chauvin, A., Roperch, P., and Duncan, R.A., 1990. Records of geomagnetic reversals from volcanic islands of French Polynesia. 2. Paleomagnetic study of a flow sequence (1.2-0.6 Ma) from the island of Tahiti and discussion of reversal models. J. Geophys. Res., 95:2727-2752.

Clement, B.M., 1992. Evidence for dipolar fields during the Cobb Mountain geomagnetic polarity reversals. Nature, 358:405-407.

Clement, B.M., and Kent, D.V., 1987. Short polarity intervals within the Matuyama: transitional field records from hydraulic piston cored sediments from the North Atlantic. Earth Planet. Sci. Lett., 81:253-264.

Clement, B.M., and Martinson, D.G., 1992. A quantitative comparison of two paleomagnetic records of the Cobb Mountain Subchron from North Atlantic deep-sea sediments. J. Geophys. Res., 97:1735-1752.

Cox, A., Doell, R.R., and Dalrymple, G.B., 1963. Geomagnetic polarity epoch and Pleistocene geochronometry. Nature, 198:1049-1051.

Gordon, R.G., 1990. Test for bias in paleomagnetically determined paleolatitudes from Pacific Plate Deep Sea Drilling Project sediments. J. Geophys. Res., 95:8397-8404.

Harland, W.B., Armstrong, R.L., Cox, A.V., Craig, L.E., Smith, A.G., and Smith, D.G., 1989. A Geologic Time Scale 1989: Cambridge (Cambridge Univ. Press).

Hoffman, K.A., 1991. Long-lived transitional states of the geomagnetic field and the two dynamo families. Nature, 354:273-277.

_ 1992. Dipolar reversal states of the geomagnetic field and coremantle dynamics. Nature, 359:789-794.

Hsu, V., Merrill, D.L., and Shibuya, H., 1990. Paleomagnetic transition records of the Cobb Mountain Event from sediments of the Celebes and Sulu seas. Geophys. Res. Lett., 17:2069-2072.

Laj, C., Mazaud, A., Fuller, M., Weeks, R., and Herrero-Bervera, E., 1991. Lateral variations at the core-mantle boundary revealed by geomagnetic reversal paths? Nature, 351:447.

Leg 135 Shipboard Scientific Party, 1991. A new view of ARC/BACKARC systems. Geotimes, 36:19-20.
Mankinen, E.A., Donnelly, J.M., and Grommé, C.S., 1978. Geomagnetic polarity event recorded at 1.1. m.y. B.P. on Cobb Mountain, Clear Lake volcanic field, California. Geology, 6:653-656.

Mankinen, E.A., Prevot, M., Grommé, C.S., and Coe, R.S., 1985. The Steens Mountain geomagnetic polarity transition. I. Directional history, duration of episodes, and rock magnetism. J. Geophys. Res., 90:10379-10417.

Merrill, R.T., and McElhinny, M.W., 1983. The Earth's Magnetic Field: Its History, Origin, and Planetary Perspective: London (Academic Press).

Parson, L., Hawkins, J., Allan, J., et al., 1992. Proc. ODP, Init. Repts., 135: College Station, TX (Ocean Drilling Program).

Prevot, M., Mankinen, E.A., Coe, R.S., and Grommé, C.S., 1985. The Steens Mountain (Oregon) geomagnetic polarity transition. 2. Field intensity variations and discussion of reversal models. J. Geophys. Res., 90:1041710448.

Rea, D.K., and Blakely, R.J., 1975. Short-wavelength magnetic anomalies in a region of rapid seafloor spreading. Nature, 255:125-128.

Thouveny, N., and Creer, K.M., 1992. Geomagnetic excursions in the past 60 ka: ephemeral secular variation features. Geology, 20:399-402.

Tric, E., Laj, C., Valet, J.-P., Tucholka, P., Paterne, M., and Guichard, F., 1991. The Blake geomagnetic event: transition geometry, dynamical characteristics and geomagnetic significance. Earth Planet. Sci. Lett., 102:1-13.

Tric, E., Valet, J.-P., Tucholka, P., Paterne, M., Labeyrie, L., Guichard, F., Tauxe, L., and Fontugne, M., 1992. Paleointensity of the geomagnetic field during the last 80,000 years. J. Geophys.Res., 97:9337-9351.

Valet, J.-P., Tucholka, P., Courtillot, V., and Meynadier, L., 1992. Palaeomagnetic constraints on the geometry of the geomagnetic field during reversals. Nature, 356:400-407.

Verosub, K.L., 1982. Geomagnetic excursions: a critical assessment of the evidence as recorded in sediment of the Brunhes epoch. Philos. Trans. R. Soc. London A, 306:161-168,

Wilson, R.L., 1970. Permanent aspects of the Earth's non-dipole magnetic field over Upper Tertiary times. Geophys. J. R. Astron. Soc., 19:417-437.

Date of initial receipt: 13 July 1992

Date of acceptance: 25 March 1993 Ms 135SR-122

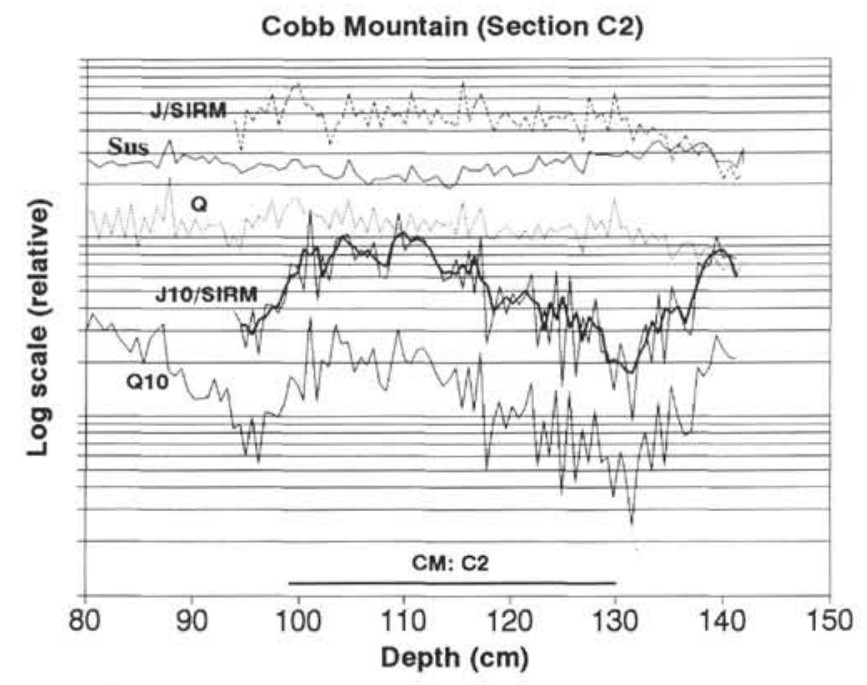

Figure 8. Rock-magnetic properties vs. depth of samples from Section C2 (CM Event at $99-130 \mathrm{~cm}$; cf. Table 1). $Q=J(\mathrm{NRM}) /$ susceptibility; $Q_{10}=J_{10} /$ susceptibility; $J_{10}$ is the remanent magnetization intensity after AF demagnetization at $10 \mathrm{mT}$; the normalized $J_{10} / \mathrm{SIRM}$ ratio is taken as a measure of the relative paleointensity of the geomagnetic field (bold line is a 3-point moving average). Units are given in Table 3. 

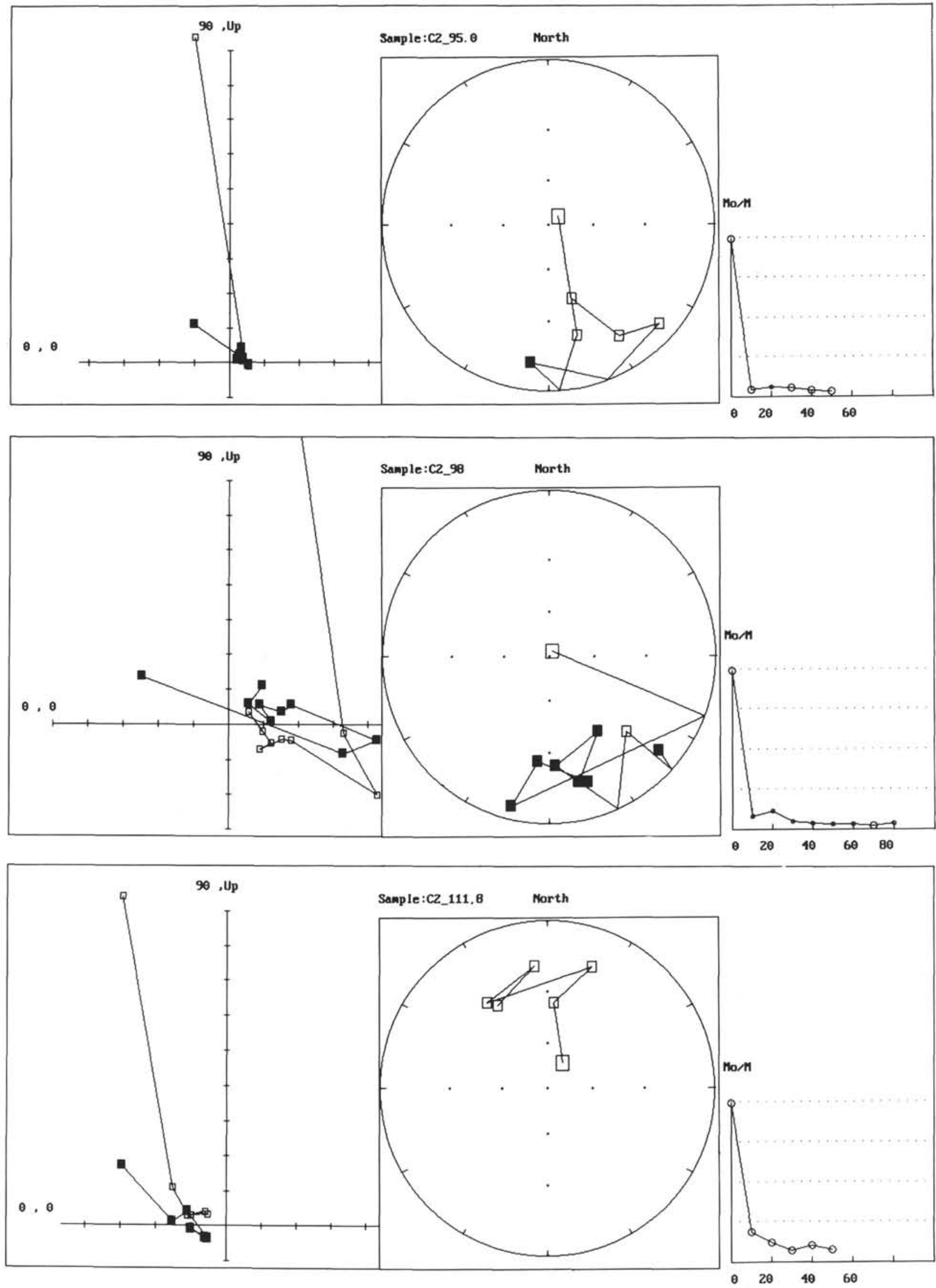

Figure 9. Orthogonal plots on the left, stereograms at center (solid/open symbols indicate positive/negative inclinations), and intensity decay curves on the right (scale in $\mathrm{mT}$ ) for $\mathrm{AF}$ demagnetization of three characteristic nannofossil ooze samples from Section $\mathrm{C} 2$. NRM intensities are given in Table 3. 


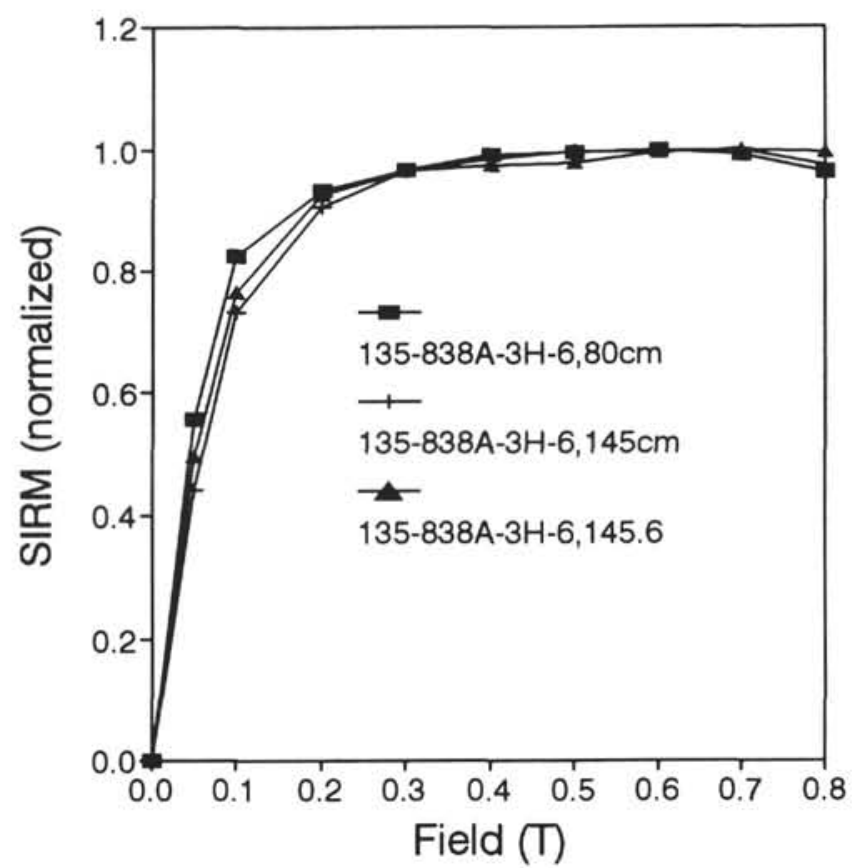

Figure 10. Saturation isothermal remanent magnetization (SIRM) acquisition curves for typical nannofossil ooze samples from Section C2. 

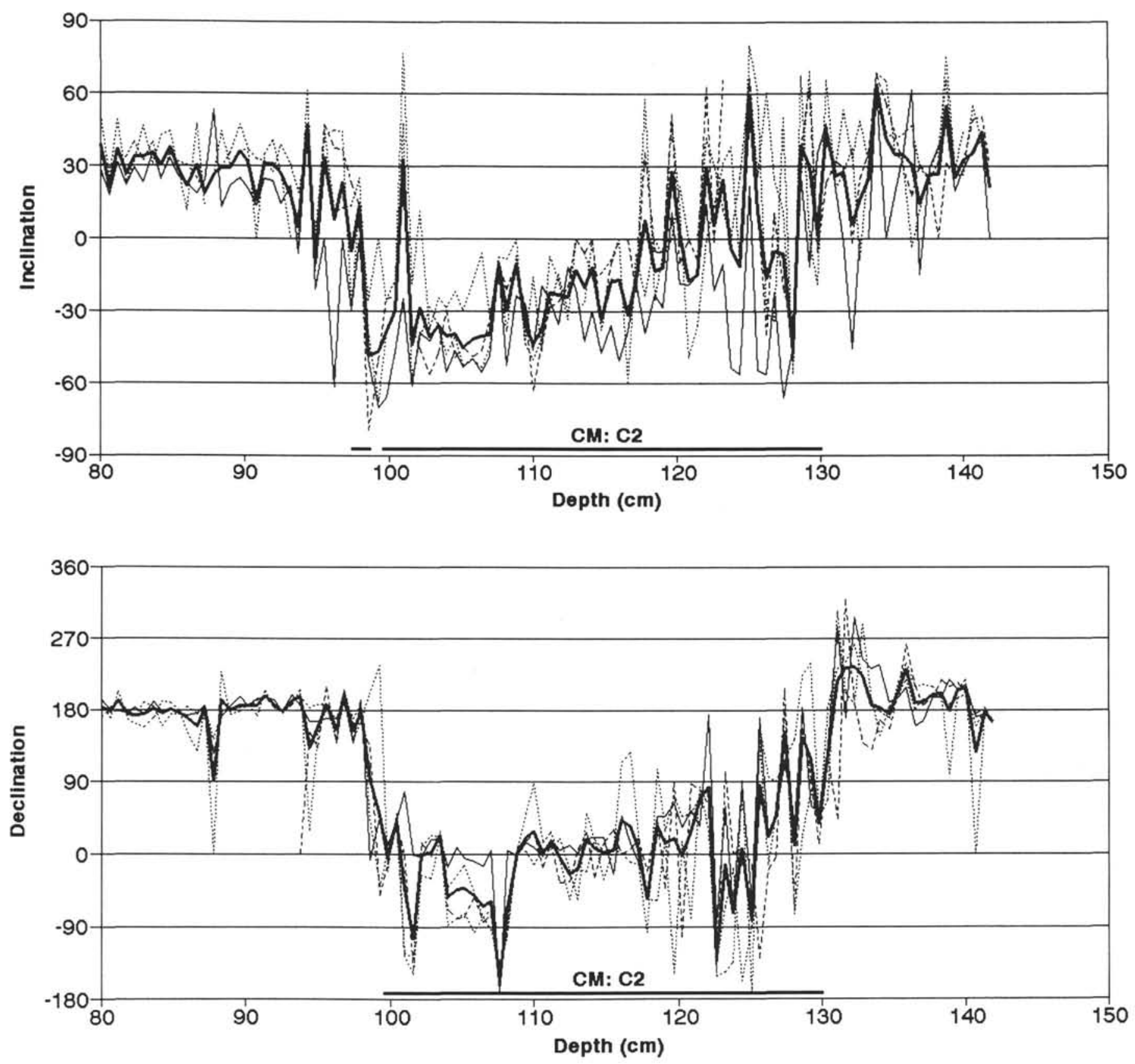

Figure 11. Declination and inclination records of Section C2 after AF demagnetization at 10,20,30, and $40 \mathrm{mT}$. Bold line is the average of the four levels. The end of Section $\mathrm{C} 2$ occurs at $99 \mathrm{~cm}$ in the declination plot, but at $98 \mathrm{~cm}$ in inclination plot (dashed line). 

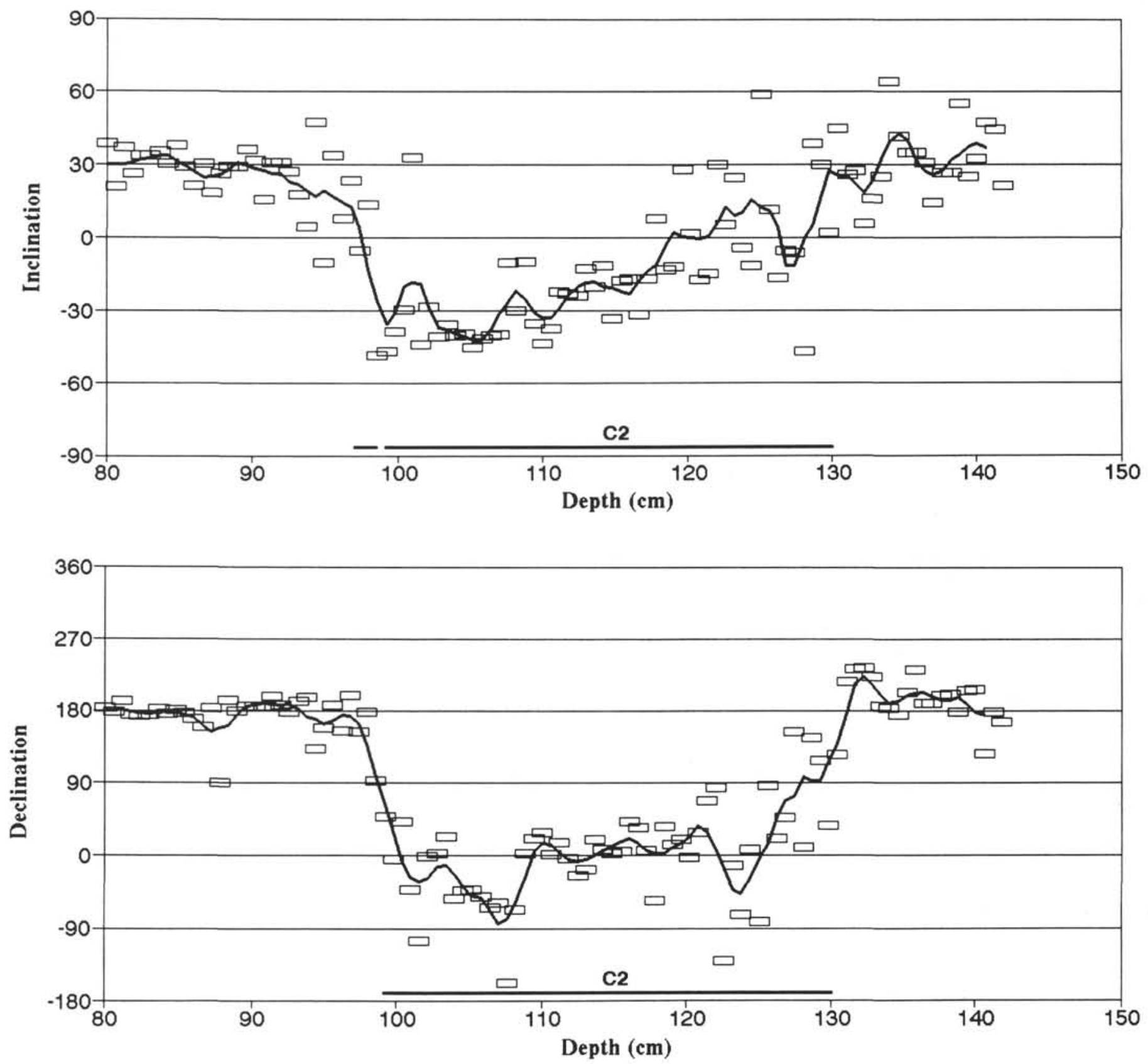

Figure 12. Smoothed declination and inclination of Section C2. Open symbols = average (at 10,20,30, and $40 \mathrm{mT}$; cf. Table 3 ) for each sample (the bold line in Fig. 11). Solid curve $=$ running mean through a window with weights $1 / 2+1+1+1+1 / 2$. 
Cobb Mountain (Section C3)

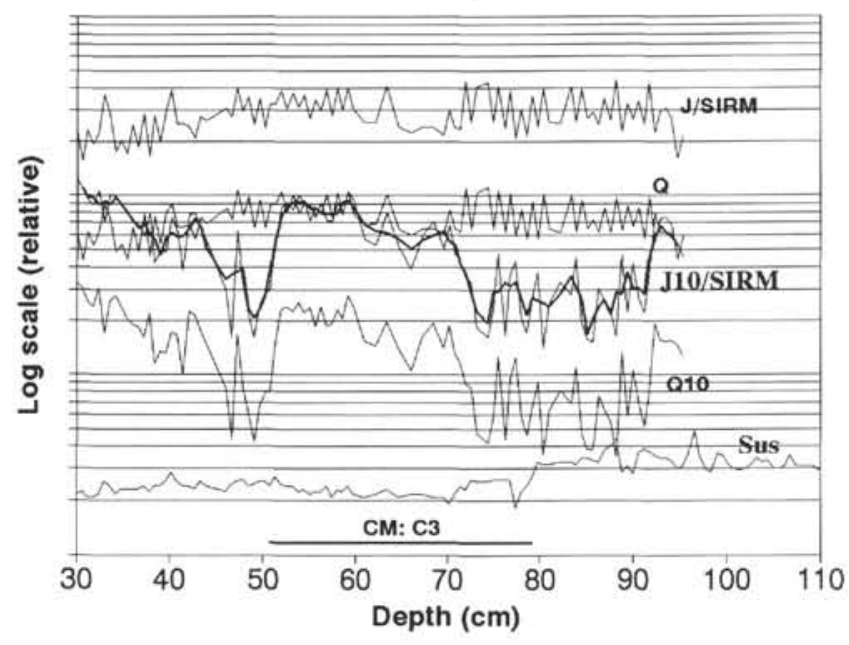

Figure 13. Rock-magnetic properties vs. depth of samples from Section C3 (CM Event at 51-79 cm; cf. Table 1). $Q=J(\mathrm{NRM}) /$ susceptibility; $Q_{10}=$ $J_{10} /$ susceptibility; $J_{10}$ is the remanent magnetization intensity after AF demagnetization in $10 \mathrm{mT}$; the normalized $J_{10} / \mathrm{SIRM}$ ratio is taken as a measure of the paleointensity of the geomagnetic field (bold line is a 3-point moving average). Units are quoted in Table 4. 
N. ABRAHAMSEN, WW. SAGER
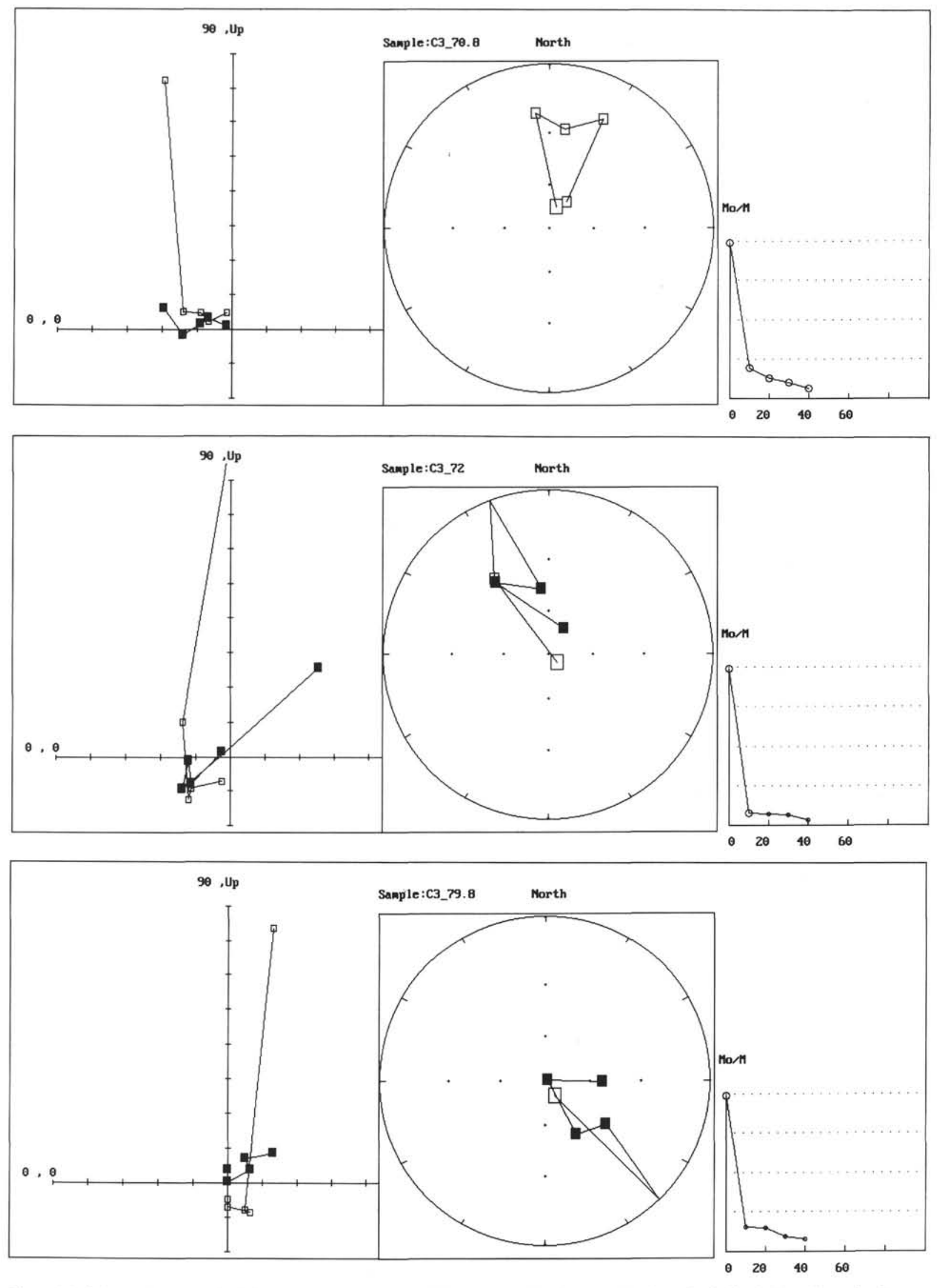

Figure 14. Orthogonal plots on the left, stereogram at center (solid/open symbol indicates positive/negative inclination), and intensity decay curves on the right (scale in $\mathrm{mT}$ ) for $\mathrm{AF}$ demagnetization of three characteristic nannofossil ooze samples from Section C3. NRM intensities are given in Table 4.

756 


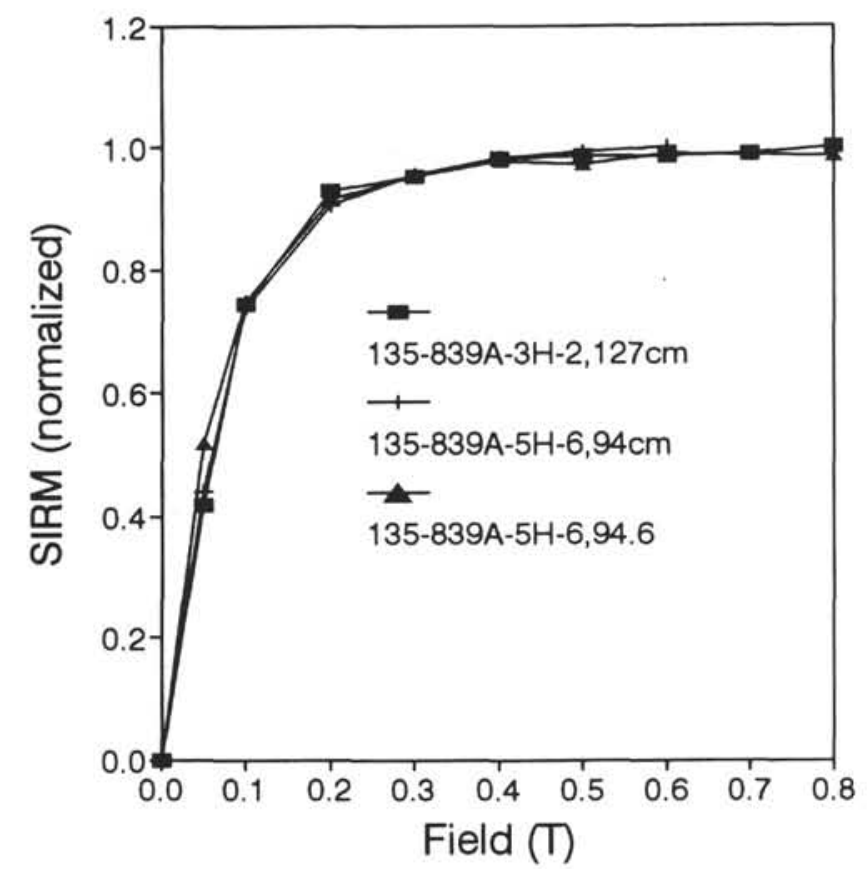

Figure 15. Saturation isothermal remanent magnetization (SIRM) acquisition curves for typical nannofossil ooze samples from Section C3. 

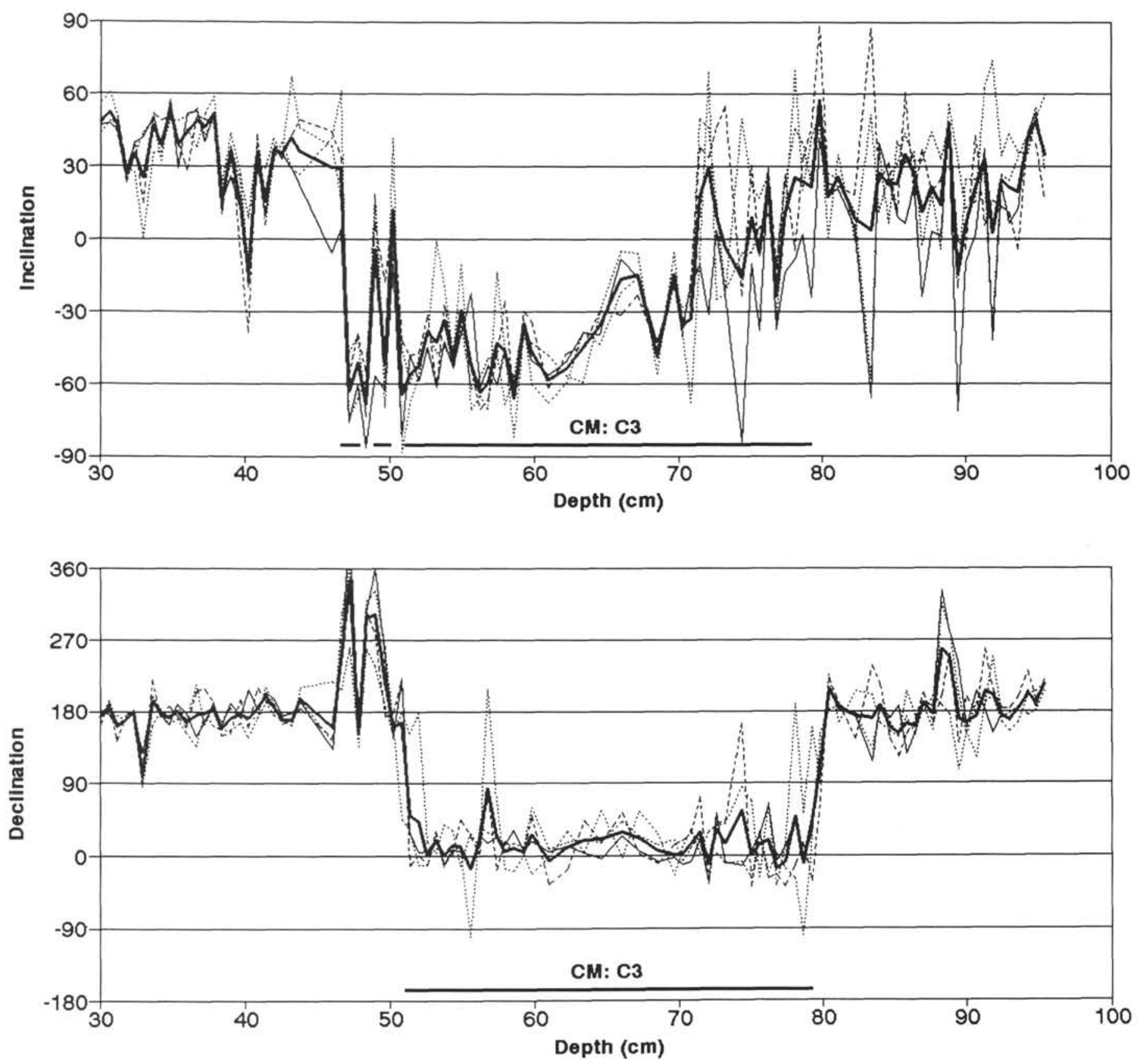

Figure 16. Declination and inclination records of Section C3 after AF demagnetization at 10,20,30, and $40 \mathrm{mT}$. Bold line is the average of the four levels. The end of Section $\mathrm{C} 3$ occurs at $51 \mathrm{~cm}$ in the declination plot, but at $47 \mathrm{~cm}$ in the inclination plot (dashed line). 

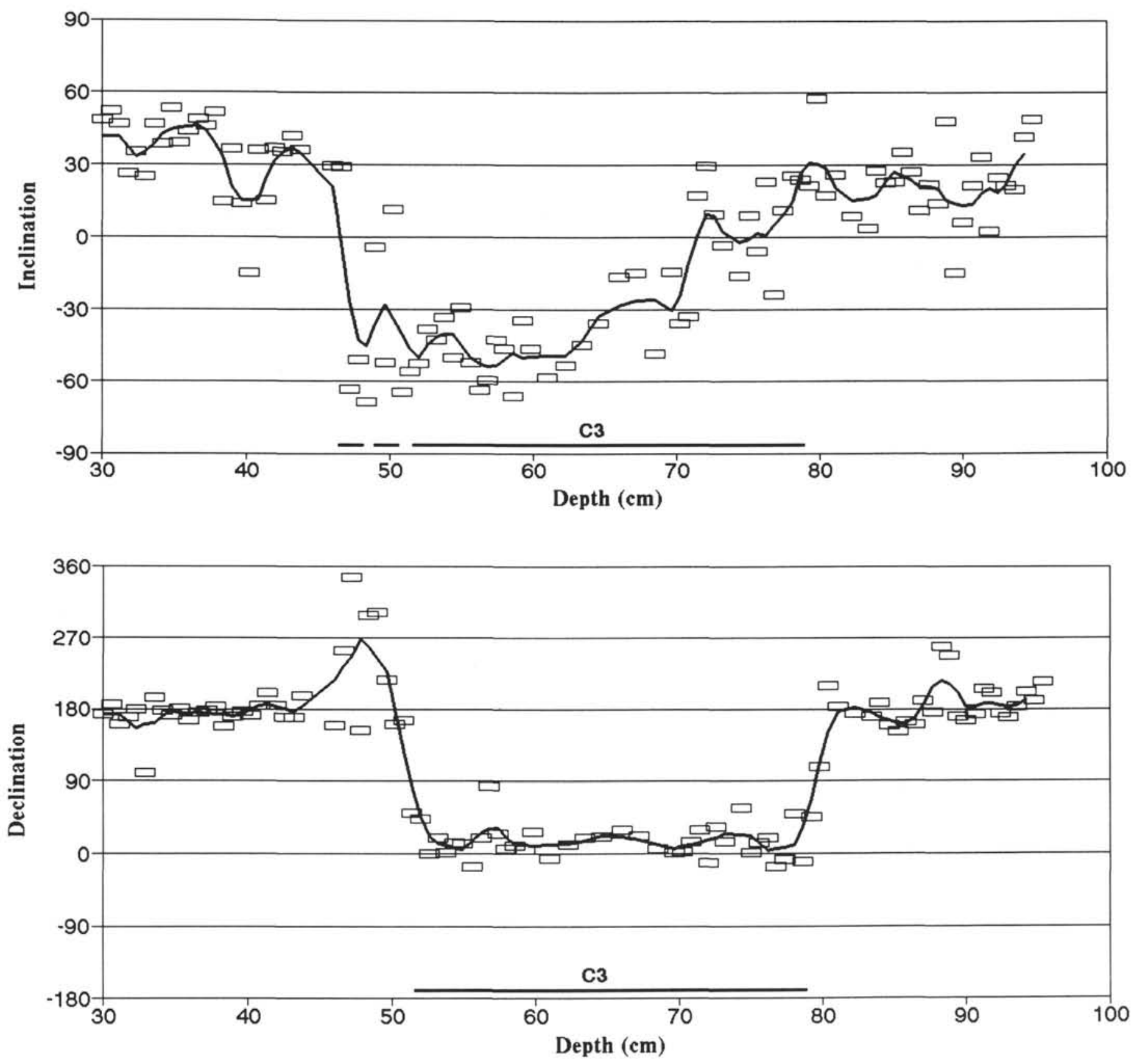

Figure 17. Smoothed declination and inclination of Section C3. Open symbols = average (at 10,20,30, and $40 \mathrm{mT}$; cf. Table 4) for each sample (bold line in Figure 16). Solid curve $=$ running mean through a window with weights $1 / 2+1+1+1+1 / 2$. 


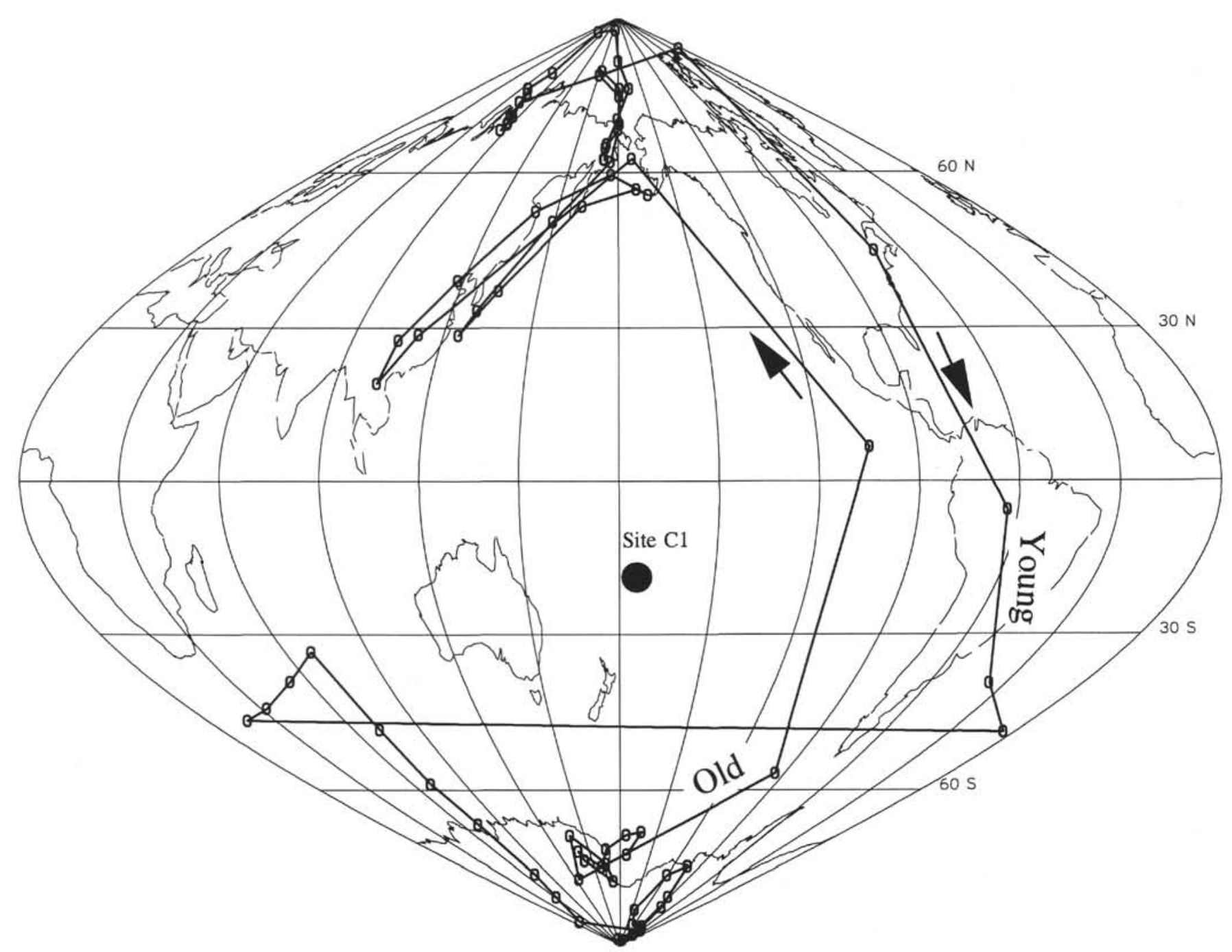

Figure 18. Apparent pole positions during the Cobb Mountain Event, Section C1 (sinusoidal equal-area projection). The poles shown are calculated from the running mean values in Figure 7. The site position is shown with a solid circle, and the two transitions are labeled old (R to $N)$ and young $(N$ to $R$ ), respectively. 


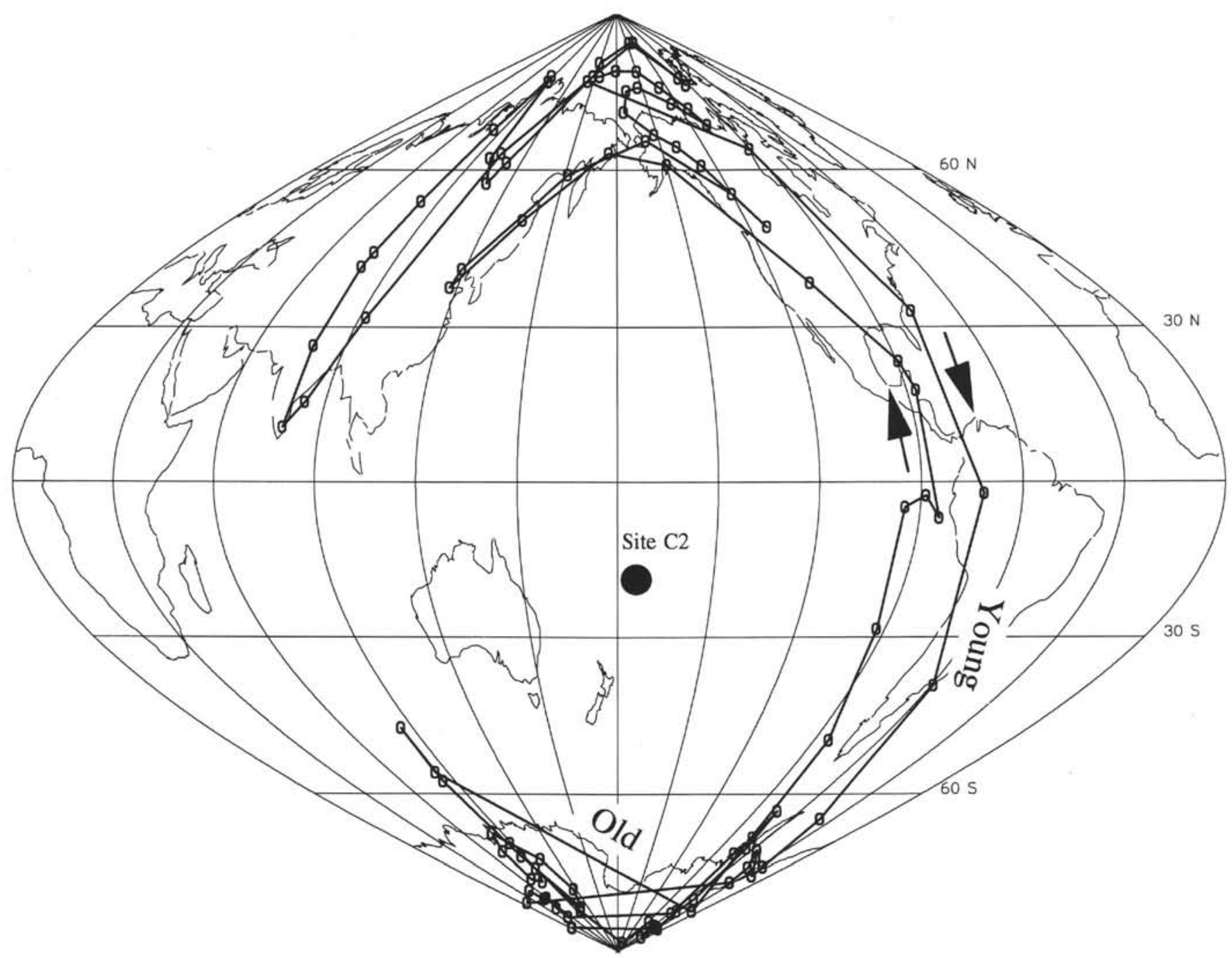

Figure 19. Apparent pole positions during the Cobb Mountain Event, Section C2 (sinusoidal equal-area projection). The poles shown are calculated from the running mean values in Figure 12. The site position is shown with a solid circle, and the two transitions are labeled old (R to N) and young (N to R), respectively. 


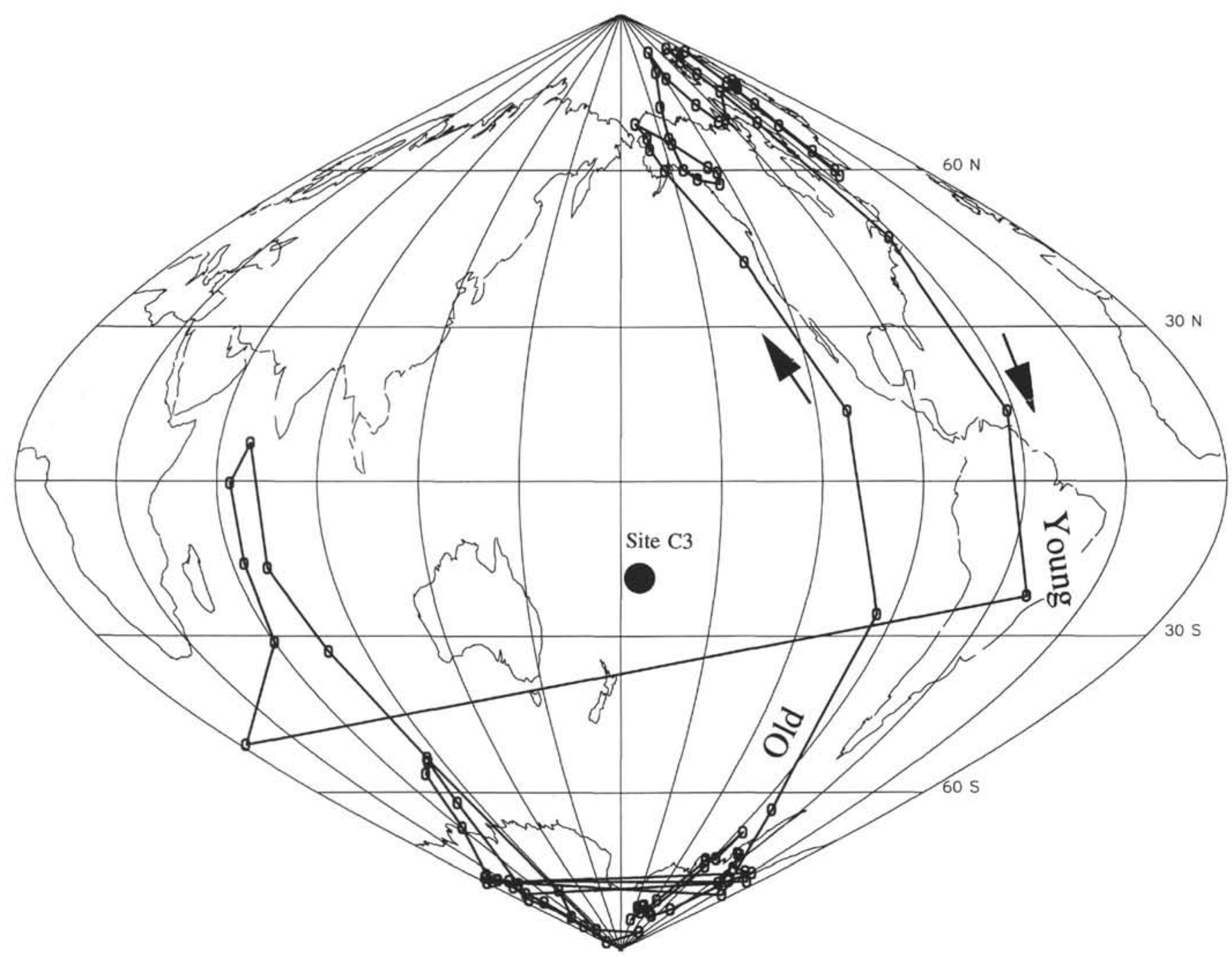

Figure 20. Apparent pole positions during the Cobb Mountain Event, Section C3 (sinusoidal equal-area projection). The poles shown are calculated from the running mean values in Figure 17. The site position is shown with a solid circle, and the two transitions are labeled old ( $\mathrm{R}$ to $\mathrm{N}$ ) and young (N to $\mathrm{R}$ ), respectively. 